Portland State University

PDXScholar

TREC Final Reports

Transportation Research and Education Center

(TREC)

3-2018

\title{
A North American Survey of Electric Bicycle Owners
}

John MacArthur

Portland State University, macarthur@pdx.edu

Michael Harpool

Portland State University

Daniel Scheppke

Portland State University

Christopher Cherry

University of Tennessee, Knoxville

Follow this and additional works at: https://pdxscholar.library.pdx.edu/trec_reports

Part of the Transportation Commons, and the Urban Studies Commons

Let us know how access to this document benefits you.

\section{Recommended Citation}

MacArthur, John, Christopher Cherry, Michael Harpool and Daniel Scheppke. A North American Survey of Electric Bicycle Owners. NITC-RR-1041. Portland, OR: Transportation Research and Education Center (TREC), 2018. https://doi.org/10.15760/trec.197

This Report is brought to you for free and open access. It has been accepted for inclusion in TREC Final Reports by an authorized administrator of PDXScholar. Please contact us if we can make this document more accessible: pdxscholar@pdx.edu. 


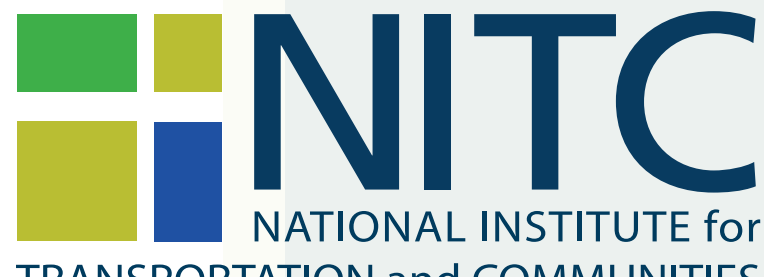

TRANSPORTATION and COMMUNITIES

FINAL REPORT

\section{A North American Survey of Electric Bicycle Owners}

NITC-RR-1041 $\quad$ March 2018

NITC is a U.S. Department of Transportation national university transportation center.

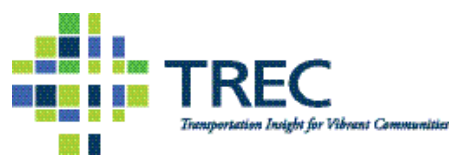





\title{
A NORTH AMERICAN SURVEY OF ELECTRIC BICYCLE OWNERS
}

\author{
Final Report \\ NITC-RR-1041 \\ by \\ John MacArthur \\ Michael Harpool \\ Daniel Scheppke \\ Portland State University \\ Christopher R. Cherry \\ University of Tennessee \\ for
}

National Institute for Transportation and Communities (NITC)

P.O. Box 751

Portland, OR 97207
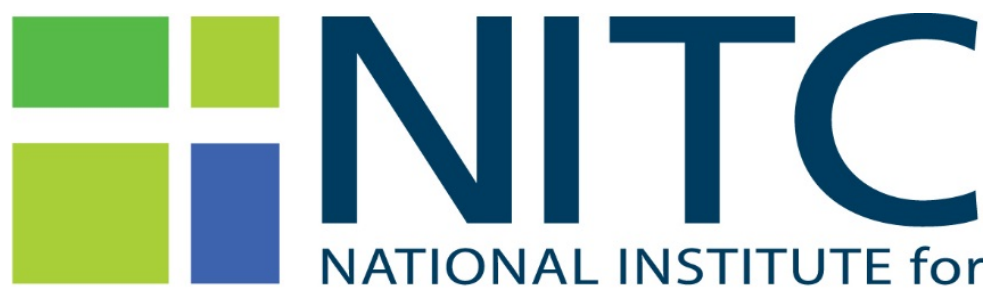

TRANSPORTATION and COMMUNITIES

March 2018 



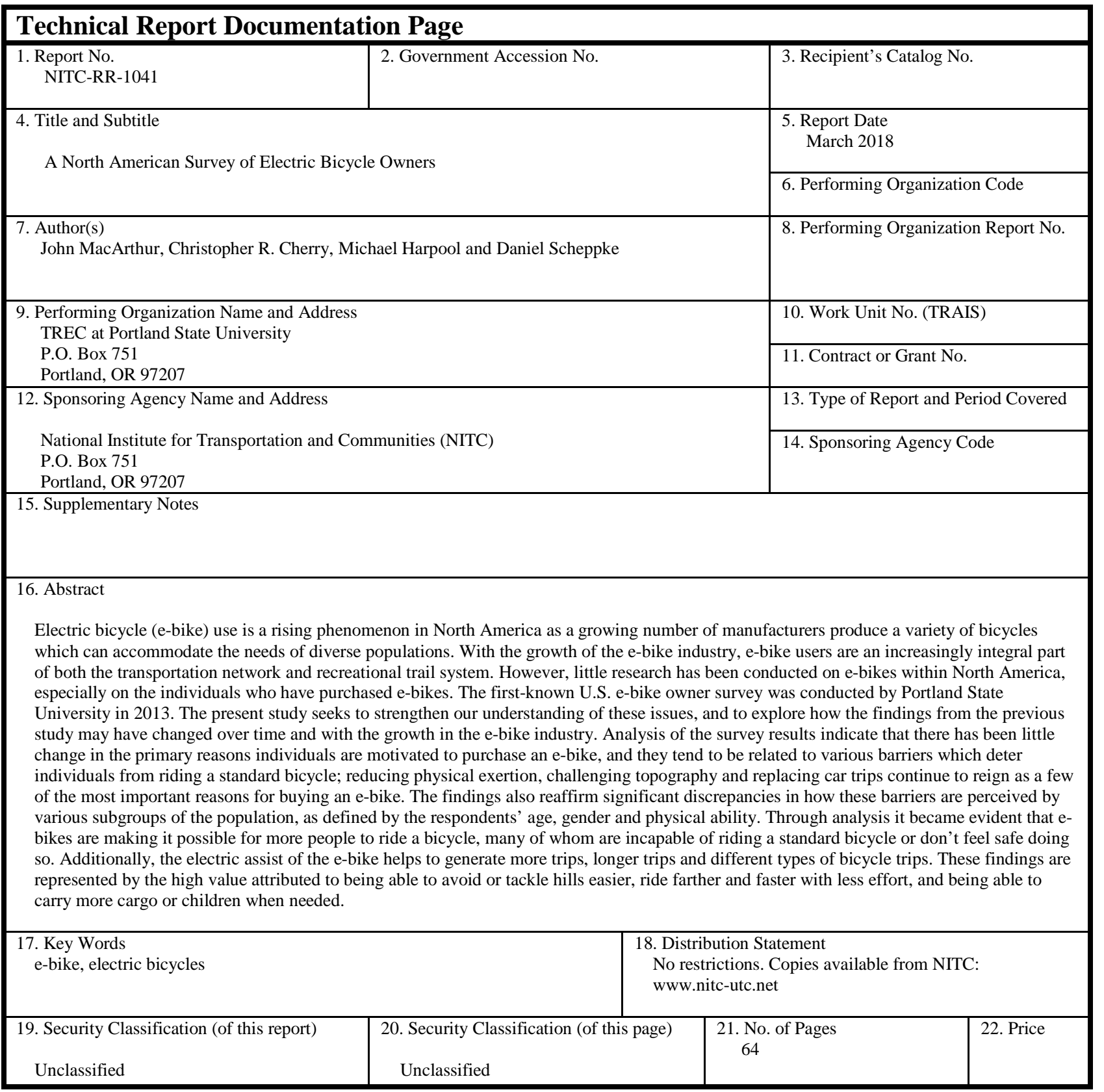




\section{ACKNOWLEDGEMENTS}

The authors would like to thank the Bicycle Product Suppliers Association (BPSA) and PeopleforBikes for funding for the project and support during the project. We would particularly like to thank Morgan Lommele from PeopleforBikes, Jonathan Weinert from Bosch eBike Systems, and Larry Pizzi from Raleigh Electric for all of their input, feedback and efforts on the project to make sure it was successful. We'd also like to thank all the respondents for their input and all the companies, organizations, and stores that helped get the word out about the survey.

This project was additionally funded by the National Institute for Transportation and Communities (NITC) under grant number 1041.

\section{DISCLAIMER}

The contents of this report reflect the views of the authors, who are solely responsible for the facts and the accuracy of the material and information presented herein. This document is disseminated under the sponsorship of the U.S. Department of Transportation University Transportation Centers Program in the interest of information exchange. The U.S. Government assumes no liability for the contents or use thereof. The contents do not necessarily reflect the official views of the U.S. Government. This report does not constitute a standard, specification, or regulation.

\section{RECOMMENDED CITATION}

MacArthur, John, Christopher Cherry, Michael Harpool and Daniel Scheppke. A North American Survey of Electric Bicycle Owners. NITC-RR-1041. Portland, OR: Transportation Research and Education Center (TREC), 2018. 


\section{TABLE OF CONTENTS}

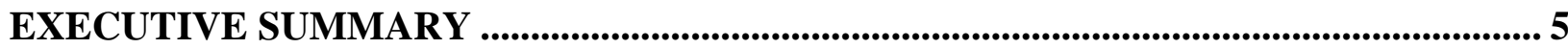

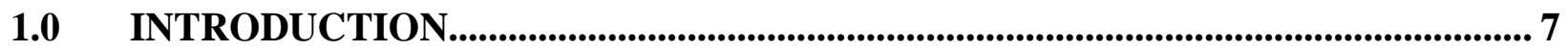

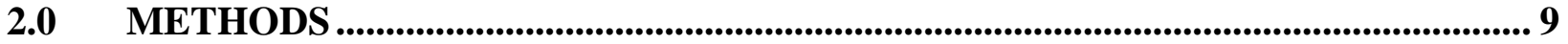

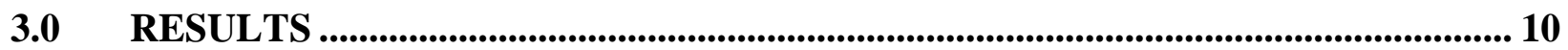

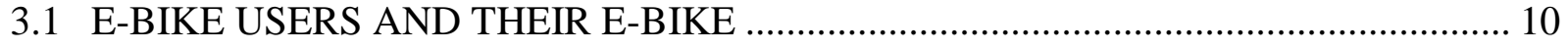

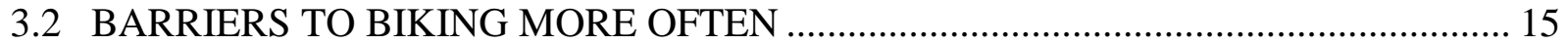

3.3 REASONS FOR BUYING OR CONVERTING TO AN E-BIKE …........................... 17

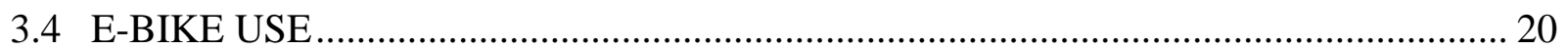

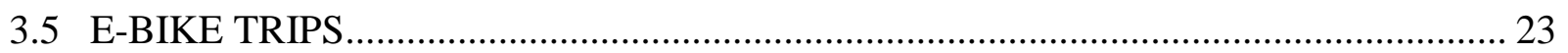

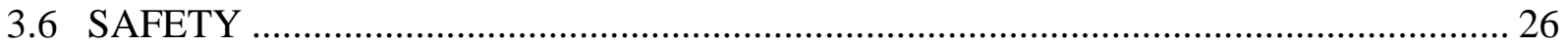

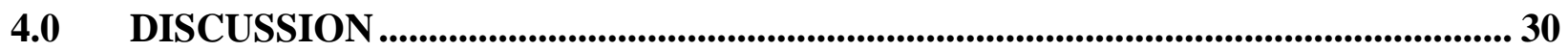

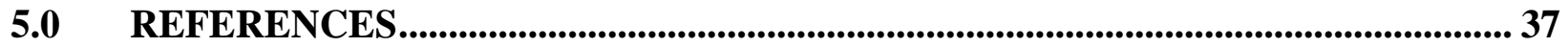

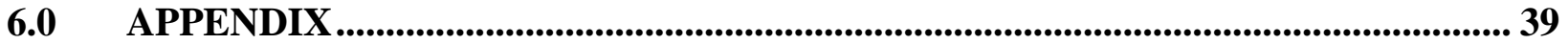




\section{LIST OF TABLES}

Table 3.1: Survey Respondents by State and Canadian Province .......................................... 11

Table 3.2: Respondent Characteristics.............................................................................. 12

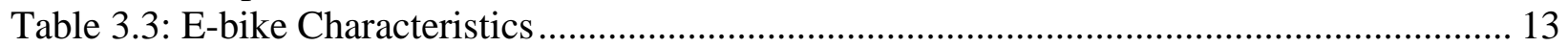

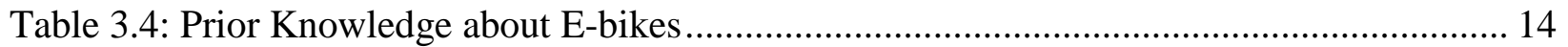

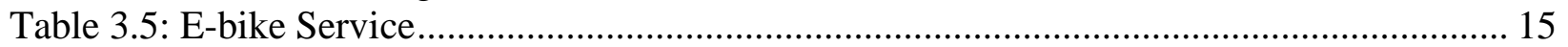

Table 3.6: Barriers that Limited Utilitarian Riding ......................................................... 17

Table 3.7: Motivations for Purchasing an E-bike ................................................................. 19

Table 3.8: Attitudes of E-bike Users by Respondent Characteristics ...................................... 22

Table 3.9: Perceptions of E-bike Use by Cyclist Type.......................................................... 23

Table 3.10: E-bike Used as Primary Mode by Respondent Characteristics ............................... 24

Table 3.11: E-bike Used as Primary Mode by Cyclist Type .................................................... 24

Table 3.12: Trips Replaced by E-bike: Mode and Average Trip Length ................................... 25

Table 3.13: Perceptions of Safety by Respondent Characteristics ......................................... 28

Table 3.14: Perceived Safety by Cyclist Type..................................................................... 29

\section{LIST OF FIGURES}

Figure 3.1: Map of Survey Respondents (excluding Alaska and Hawaii)................................. 10

Figure 3.2: Mode Used for Various Trip Types Made by Respondents ................................... 12

Figure 3.3: Important Considerations at Time of Purchase ................................................ 14

Figure 3.4: Important Barriers to Riding a Standard Bicycle ................................................. 16

Figure 3.5: Important Reasons for Buying or Converting to an E-bike.................................... 18

Figure 3.6: Bike Ridership Rates .............................................................................. 20

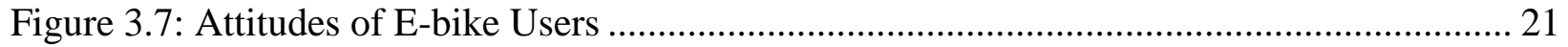

Figure 3.8: Percentages of Trip Types, Based on Respondents Three Most Recent E-bike Trips 25

Figure 3.9: Perceived Conflict with Other Mode Types....................................................... 27 


\section{EXECUTIVE SUMMARY}

Electric bicycle (e-bike) use is a rising phenomenon in North America as a growing number of manufacturers produce a variety of bicycles which can accommodate the needs of diverse populations. With the growth of the e-bike industry, e-bike users are an increasingly integral part of both the transportation network and recreational trail system. However, little research has been conducted on e-bikes within North America, especially on the individuals who have purchased e-bikes. The first-known U.S. e-bike owner survey was conducted by Portland State University in 2013. The 2013 survey aimed to understand whether e-bikes have the capacity to reduce barriers known to deter individuals from riding a standard bicycle for any given trip, including trip distance, topography, time and physical exertion. The authors believed that if these barriers could be reduced by the electronic assist of the e-bike, then the propensity for diverse groups of individuals to bicycle could increase, especially for populations known to be disproportionately impacted by these barriers such as females, older adults and those with a physical limitation. Additionally, e-bikes provide the potential for individuals to ride to further destinations, ride more and carry more cargo. Through these interrelated benefits e-bikes may increase the diversity of people bicycling, increase distances traveled by bicycle, and change the purposes for which bicycles are used. The present study seeks to strengthen our understanding of these issues, and to reveal whether the findings from the previous study have changed over time and with the growth in the e-bike industry. This study also hopes to overcome multiple limitations of the first study by targeting a larger portion of the population by connecting with ebike manufacturers and enhancing survey distribution techniques, and by asking respondents a refined and expanded set of questions. Additional questions also permit the researchers to delve into topics underexplored or unexplored in the 2013 study, including safety implications and mode replacement. This report looks to present the results of the 2017 survey and compares results to the 2013 study when appropriate. The data of the two surveys are not statistically compared in this report but may be done in future analysis.

This current survey was distributed online through e-bike blogs and forums, multiple social media platforms, manufacturer and retailers' e-mailing lists, and cards left on e-bikes throughout the Portland, OR, area. A total of 1,796 respondents who own or regularly operate an e-bike within North America completed the survey. Their responses were analyzed utilizing SPSS statistical software. The sample of e-bike users was not collected randomly, and as such findings may not be completely representative of the population being studied. However, given the lack of previous research and limited understanding of e-bike ownership in North America, this strategy is suitable for the present research goals.

Analysis of the survey results indicate that there has been little change in the primary reasons individuals are motivated to purchase an e-bike, and they tend to be related to various barriers which deter individuals from riding a standard bicycle; reducing physical exertion, challenging topography and replacing car trips continue to reign as a few of the most important reasons for buying an e-bike. The findings also reaffirm significant discrepancies in how these barriers are

perceived by various subgroups of the population, as defined by the respondents' age, gender and 
physical ability. Older adults and those with a physical limitation are more highly motivated by factors related to reducing the effort of riding and health, fitness and recreation. On the other hand, younger adults and those without a physical limitation are more highly motivated by factors related to replacing car trips and making their commute easier, quicker and more cost effective. Furthermore, females are more concerned with topography, carrying cargo or children, and being able to keep up with friends and family on bicycle rides when compared to males. These motivations are directly related to discrepancies in how various populations tend to use their e-bike; younger adults and individuals without physical limitations reported utilizing their e-bike more heavily for utilitarian purposes rather than recreation and exercise, and the opposite is true for older adults and those with a physical limitation.

Through analysis of the survey responses, it became evident that e-bikes are making it possible for more people to ride a bicycle, many of whom are incapable of riding a standard bicycle or don't feel safe doing so. Additionally, the electric assist of the e-bike helps to generate more trips, longer trips and different types of bicycle trips. These findings are represented by the high value attributed to being able to overcome hills easier, ride farther and faster with less effort, and being able to carry more cargo or children when needed. Thus, making daily utilitarian trips easier for some and enhancing recreational opportunities for those who desire such activity. When the respondents' most recent e-bike trips were analyzed, the results indicated that e-bikes have the capacity to replace various modes of transportation commonly used for utilitarian and recreational trips, including motor vehicles, public transit and standard bicycles. The majority of the utilitarian trips (i.e., errands and commutes) being made by e-bike are replacing motor vehicle trips, which signifies an impressive decrease in vehicle miles traveled. With increasing concern for reducing emissions by motor vehicles and minimizing the congestion of motor vehicles in urban and suburban areas, e-bikes can serve as a healthier and cleaner way to travel. This is especially important when considering how e-bikes make longer trips more feasible, as distance to destinations is a key deterrent to riding a standard bicycle. Thus, e-bikes could potentially serve as a practical means of transportation for people who live in the suburbs and have a longer commute.

Although it is not clear if creating a safer trip is a key factor in the decision to purchase or convert to an e-bike, this report reveals that many respondents feel safer riding an e-bike than they do a standard bicycle and they value an enhanced sense of safety. With the help of the electric assist, e-bike users can take longer routes to avoid utilizing dangerous streets, they can accelerate quickly to get through wide intersections or away from a potential conflict, and they are able to keep up with the pace of traffic which minimizes the speed differential. Respondents were approximately eight times more likely to report that their e-bike has helped them avoid a crash than they were to report that their e-bike has significantly contributed to a crash; however, as vulnerable users of the transportation system they often have conflicts with motor vehicles. In addition to the conflicts that are shared with standard bicyclists, such as inattentive drivers and poor shared-road conditions, e-bike users face the danger of motorists misjudging their speed. Perceived safety plays an essential role in whether an individual is likely to ride a bicycle for a given trip; thus, by enhancing one's sense of safety e-bikes could potentially tap latent demand for bicycling by encouraging those who may not feel safe on a standard bicycle. Supportive and protective policies could help cities capitalize on the numerous environmental and social benefits e-bikes have to capacity to generate. 


\subsection{INTRODUCTION}

Electric bicycles (e-bikes) are a new mode of transportation that could substantially improve efficiency in the transportation system if adopted, especially if they substitute for car use. Ebikes are relatively simple device and have electric motors to assist riders, generally through pedal assistance. They take different form factors and have a wide array of performance characteristics, and as such they are regulated differently across jurisdictions (MacArthur \& Kobel, 2014). In recent years, there has been a movement to standardize electric bicycle regulations around the country into a three-class system that categorizes electric bicycles based on their maximum assisted speed and power assist mechanism (PeopleforBikes, 2017).

The worldwide market for e-bikes is growing but varies geographically. Worldwide sales of ebikes were estimated to be 36 million units in 2015 and 100 million by 2035, with the majority of sales being in Asia (Benjamin \& Jamerson, 2015). In particular, over 200 million e-bikes were operating in China (Benjamin \& Jamerson, 2015). In the U.S., e-bikes are a small but growing market, with estimated sales in 2016 of 200,000-250,000 units. Since there is no data source that aggregates e-bike sales at the city or state level, it is impossible to determine areas and cities of high adoption. Because of limited numbers in North America, e-bikes can still be considered in the "early adopter" phase, though U.S. consumers are being presented with a broader range of ebike options through specialty bicycle stores, online and other retail outlets. Mainstream use of ebikes in the U.S. had been hampered by small production volumes, cost and lack of knowledge about the technology. Issues affecting general bike use, such as inadequate infrastructure investments and a lack of comprehensive, integrated policies and programs to promote bicycling and cycling safety, also impact e-bike use (Pucher \& Buehler, 2011). Even in a city like Portland, OR, with comprehensive, robust bicycling infrastructure, programs and policies that resulted in a six-fold increase in cycling levels from 1990 to 2010, e-bikes face difficulty in moving beyond early adopters and allowing more users to become interested in using them (Dill \& Rose, 2011; Pucher \& Buehler, 2011). This may be changing with a board array of e-bikes now on the market and at different price categories.

Previous research has identified that some primary barriers to encouraging new people to bicycle include inconvenience, safety and amount of effort required to bike, including distance traveled and physical limitations (Heinen et al., 2010). By providing electric assist to a rider, the potential for the role of the bicycle, especially for commuting, can be expanded by addressing the limits of trip distance and terrain. E-bikes could allow people with physical limitations, older adults and people in geographically challenging areas to participate in bicycling (Dill \& Rose, 2011; MacArthur et al., 2014).

There has been a growing body of literature on e-bike use and behavior. The majority of research dedicated to e-bikes focuses on Asian and European countries, in particular China (Fishman \& Cherry, 2015). Conversely, only a limited amount of research exists focused on the U.S. (Fishman \& Cherry, 2015; Dill \& Rose, 2011). Research is needed to create a more systematic and detailed description of the range of measures, policy instruments, and technological and industry dynamics necessary to support e-bikes (Hamdouch \& Depret, 2010). There is a need for a greater understanding of the early adopters and the role that e-bikes might play in household mobility decisions, particularly the potential for substituting for auto trips or supplementing 
transit trips. In discussions with industry representatives, their perceived market for e-bikes has been older adults and people wanting to cycle for recreational purposes. Using surveys supplemented by GPS data collected from the first mixed e-bike and conventional bicycle sharing program in North America, Langford, Cherry et al. (2013) found e-bike users also replaced $11 \%$ of car trips compared to very few car trips replaced by users of conventional bicycles. Using instrumented bikes, Langford, Chen et al. (2015) also found e-bike and bicycle riders behave very similarly in traffic but there were some speed differences, which raises questions around safety. In a 2017 study, Ling et al. compared the discrepancies in cycling experience and perception between e-bike and standard bicycle users. They found that e-bikes play a more significant role in utilitarian travel than do standard bicycles, and that e-bike users tend to ride farther and take more trips by bicycle. They also developed a model to evaluate potential e-bike purchase intention; their results suggest that travel purpose, e-bike familiarity, reason for cycling, annual household income, and education level are all significant factors influencing interest in future e-bike ownership.

This project is based on a survey conducted in 2013 by the authors (MacArthur et al., 2014). The results suggested that e-bikes enabled users to bike more often and bike farther. E-bikes also gave people who otherwise would not be able to bike (because of physical limitations or proximity to locations) the ability to overcome these challenges.

In the first survey, the demographics of respondents showed a predominately male (85\%), 45 years of age or older (71\%), white (90\%), college graduates (71\%), and in very good or excellent health (58\%). Nearly one-third of respondents (30\%) stated that they had a physical condition that makes riding a standard bike difficult; the conditions commonly listed were knee problems, arthritis, asthma and back pain. Nearly $65 \%$ of respondents stated that one of the main reasons why they bought or converted an e-bike was to replace some car trips; $21 \%$ reported having a medical condition that reduced their ability to ride a standard bike; and 52\% wanted to increase fitness. Nearly $60 \%$ of respondents indicated that one of the main reasons was because they lived or worked in a hilly area, and 55\% wanted to ride with less effort. The smallest percentage of respondents (11\%) said they bought or converted to an e-bike to keep up with friends or family.

One of the stated primary advantages of e-bikes is the ability to bike with less effort, which applies differently in different populations. Older adults and people with physical limitations found biking easier and not as strenuous. Younger people can travel farther and not exert enough effort to perspire while riding. Survey respondents reported riding their e-bike more than they rode their standard bike prior to their e-bike purchase (if they rode at all), indicating a positive relationship between having an e-bike and increased riding. Respondents also indicated that they are biking farther distances but are less sweaty or tired than with a standard bicycle; they do not avoid certain trips, destinations or hills; and they enjoy the experience of bike riding.

There are many open questions about the role of e-bikes in the transportation system (e.g., safety, health, sustainability). Unlike some technologies, e-bikes are a class of vehicle whose performance characteristics could stimulate different user behavior than of conventional bicyclists. Sizable shifts toward e-bikes from heavier motorized modes could improve sustainability in the transportation system. Understanding the reasons people purchase their ebike and how they use it is important to understand the potential of these bikes to get more people biking and more people biking more often. 


\subsection{METHODS}

The goal of the study was to learn from people who either own or often use e-bikes about their experiences purchasing, owning and riding their bikes. The study used an online survey to ask ebike owners questions about these experiences.

The survey was adapted from a 2013 TREC study "E-bikes in North America: Results from an Online Study" (MacArthur et al., 2014). Researchers used the study as a template to create an updated survey. The final survey and procedure was approved by PSU's Human Subjects Research Review Committee (HSRRC).

The survey was hosted online using PSU's Qualtrics website (wwwtinyurl.com/ebikestudy). It was open from April 21 until July 10, 2017. The link to the survey was primarily distributed online through social media platforms like Facebook, Twitter, Instagram and online message boards. The main platforms that were used were the TREC Electric Bicycle Research Facebook page (@EBike.PSU); Light Electric Vehicle Education and Research Initiative (LEVER); Instagram (@LEVresearch); and the LEVER Initiative (@LEVresearch) and TREC (@TREC_EV) twitter accounts.

E-bike shops/dealers and manufacturers helped promote the survey. The survey was publicized on bicycle blogs. Also, about 100 postcards promoting the survey were given to e-bike riders and left on parked e-bikes in Portland. To encourage people to take part in the study, respondents were given an opportunity to enter a prize drawing for \$50 Amazon gift certificates upon completion of the survey.

The survey contained 64 questions organized into seven sections (see Appendix). In section one, respondents answered questions about their e-bike. In section two, respondents provided information about their experiences purchasing an e-bike or converting a standard bike. In section three, respondents gave details about their transportation behavior. In section four, respondents answered questions about their perceptions of safety riding an e-bike and provided information about accidents that they have had on their e-bike. In section five, respondents' answered questions about their cycling behavior before purchasing an e-bike. Section six contained open-ended questions about experiences with the e-bike. Section seven contained demographic questions. To limit the length of the survey, at the end respondents were given the option to answer more questions. The optional section asked respondents for more information about purchasing and riding their e-bike, and also included questions about e-bike servicing.

Closed-end responses were analyzed with SPSS statistical software to identify trends and differences. The survey included several questions that gave respondents the opportunity to include open-ended text responses. These responses were analyzed, coded and grouped by major theme, where possible. For groupings difference-gender, age, physical limitations, amount of cycling-we calculated standardized adjusted chi-square residuals in SPSS. By convention, residuals with absolute values of two or greater indicate a likely statistically significant $(\mathrm{p}<=0.05)$ difference for a group. 


\subsection{RESULTS}

\subsection{E-BIKE USERS AND THEIR E-BIKE}

Figure 3.1 shows the distribution of survey respondents throughout the contiguous United States and Canada. Large clusters are visible around many major cities and metropolitan areas, especially San Francisco and Los Angeles. Furthermore, Table 3.1 gives a count of surveys from each state and Canadian province. The sample accounts for all 50 states and the District of Colombia. The states with the highest number of survey respondents were California, Oregon and Washington; combined, these states accounted for approximately half of the sample. The states with the fewest respondents were West Virginia, Kentucky, North Dakota and Wyoming. The total number of survey respondents is 1,796, of which 1,663 were from the U.S. and 133 from Canada.

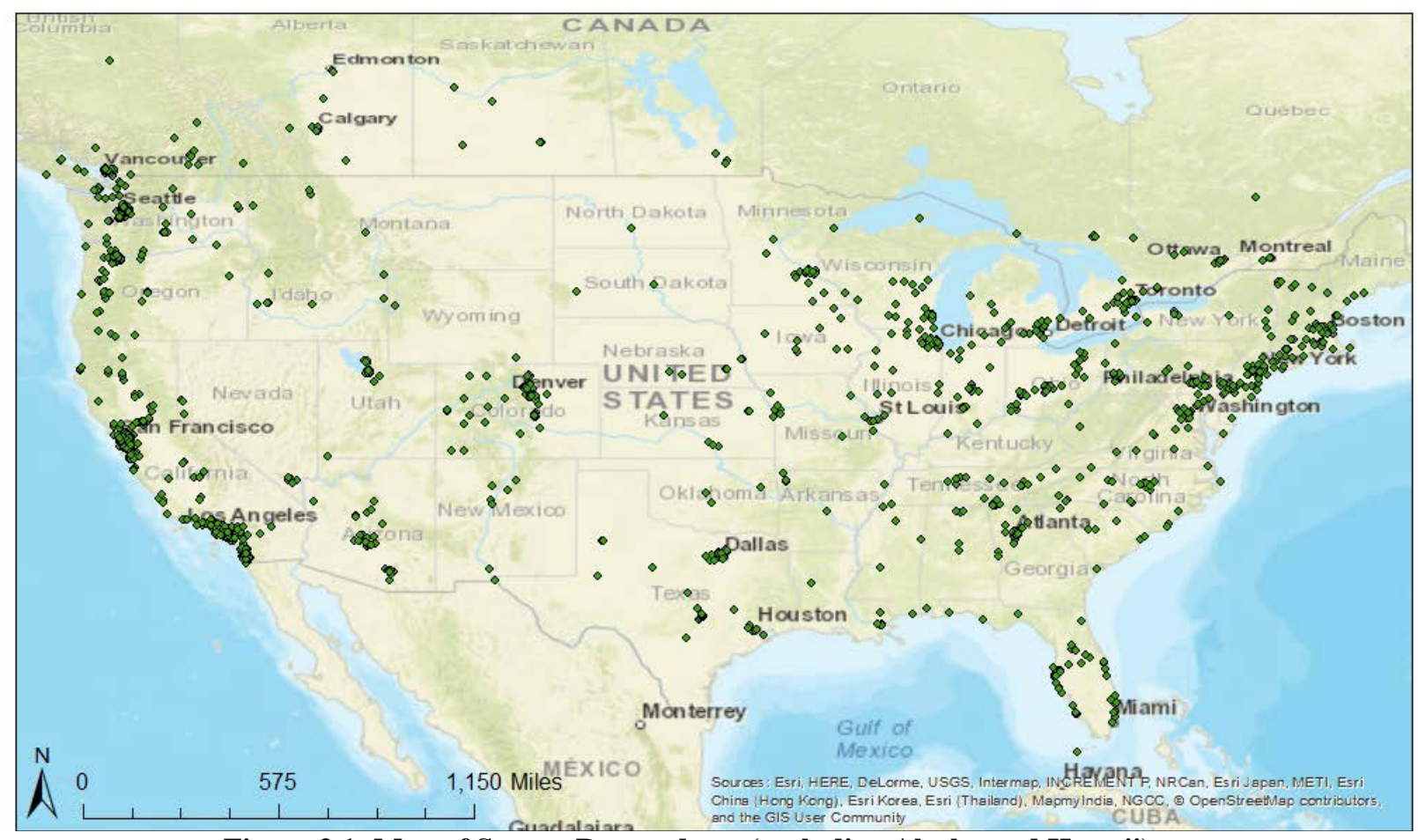

Figure 3.1: Map of Survey Respondents (excluding Alaska and Hawaii)

Note: locations on the map represent individual survey responses. 
Table 3.1: Survey Respondents by State and Canadian Province

\begin{tabular}{|c|c|c|c|c|c|c|c|}
\hline United States & Count & & & & & & \\
\hline Alabama & 6 & Iowa & 9 & New Jersey & 16 & Vermont & 12 \\
\hline Alaska & 9 & Kansas & 8 & New Mexico & 8 & Virginia & 32 \\
\hline Arizona & 34 & Kentucky & 1 & New York & 28 & Washington & 151 \\
\hline Arkansas & 5 & Louisiana & 6 & North Carolina & 24 & West Virginia & 1 \\
\hline California & 402 & Maine & 6 & North Dakota & 2 & Wisconsin & 25 \\
\hline Colorado & 69 & Maryland & 13 & Ohio & 43 & Wyoming & 2 \\
\hline Connecticut & 11 & Massachusetts & 36 & Oklahoma & 3 & Canada & Count \\
\hline Delaware & 3 & Michigan & 28 & Oregon & 286 & Alberta & 11 \\
\hline District of Columbia & 15 & Minnesota & 29 & Pennsylvania & 42 & British Columbia & 56 \\
\hline Florida & 45 & Mississippi & 5 & Rhode Island & 7 & Manitoba & 3 \\
\hline Georgia & 27 & Missouri & 13 & South Carolina & 8 & Newfoundland & 1 \\
\hline Hawaii & 5 & Montana & 4 & South Dakota & 3 & Nova Scotia & 5 \\
\hline Idaho & 11 & Nebraska & 7 & Tennessee & 32 & Ontario & 47 \\
\hline Illinois & 32 & Nevada & 10 & Texas & 47 & Quebec & 5 \\
\hline Indiana & 21 & New Hampshire & 4 & Utah & 17 & Saskatchewan & 5 \\
\hline
\end{tabular}

The survey respondents were predominately white (85.4\%), male (70.5\%), 45 years and older (67.2\%), highly educated (64.2\% with a bachelor's degree or higher), and in very good or excellent health (self-reported; 53.1\%) (Table 3.2). Despite the latter remark, only 26.9\% of the respondents report getting at least 30 minutes of moderate physical activity six or more days a week (6.5\% for vigorous activity), and $28.7 \%$ reported having a physical limitation that makes riding a standard bicycle difficult. Approximately $65 \%$ of those who reported having a physical limitation were 55 years or older, and $60 \%$ who reported no physical limitation were younger than 55 years. The physical limitations commonly cited were characterized as physical/mobility (knee problems, back pain, arthritis); respiratory/heart (asthma, cardiovascular disease); weight (obesity); dexterity (dizziness, fatigue); and hearing/vision (partial blindness, loss of hearing).

The majority of the respondents lived in households with one or more children (64.0\%); the ability to carry or ride with children was a commonly cited benefit of buying an e-bike, as one respondent notes: "I can take my kids all over the city without having to consider elevation gains, or parking. My children are more involved and social, and interact more” (anonymous respondent). Other predominant characteristics of e-bike users included: having access to one or more bicycles (97.4\%); having at least one vehicle in the household (92.3\%); having a driver's license (95.4\%); and a household income of over \$75,000 (57\%) (Table 3.2). Respondents were asked what percent of their weekly trips are made by different modes, the mean percentages for each mode are as follows: car (50.3\%); e-bike (34.6\%); standard bicycle (5.1\%); public transit (3.7\%); walking (5.4\%); and other (.9\%). The "other" category represents modes such as ride share, car share, and motorcycles and scooters. Results show that the e-bike is the most common primary mode for commute trips to work and school (34.0\%) and recreation trips (44.5\%); and driving alone or with someone else is the most common mode for running personal errands (48.8\%), visiting friends and family (35.6\%), and entertainment, dining out and socializing (34.0\%) (Figure 3.2). 
Table 3.2: Respondent Characteristics

\begin{tabular}{|c|c|c|c|}
\hline Gender $(\mathrm{n}=1,616)$ & Value (\%) & Education $(\mathrm{n}=1,626)$ & Value (\%) \\
\hline Male & 70.5 & High school or less & 5.1 \\
\hline Female & 28.5 & Some college & 21.8 \\
\hline Other & 0.2 & Associates degree & 7.6 \\
\hline I prefer not to answer & 0.7 & Bachelor's degree & 30.3 \\
\hline Age (years) $(\mathrm{n}=1,598)$ & & Graduate degree & 33.9 \\
\hline 18 to 24 & 2.3 & I prefer not to answer & 1.3 \\
\hline 25 to 34 & 10.6 & Health $(n=1,622)$ & \\
\hline 35 to 44 & 19.9 & Poor & 2.0 \\
\hline 45 to 54 & 20.1 & Fair & 10.4 \\
\hline 55 to 64 & 27.9 & Good & 34.0 \\
\hline 65 or older & 19.2 & Very good & 37.4 \\
\hline Ethnicity $(\mathrm{n}=1,623)$ & & Excellent & 15.7 \\
\hline American Indian or Alaska Native & 0.7 & I prefer not to answer & 0.6 \\
\hline Asian & 4.1 & \multirow{3}{*}{\multicolumn{2}{|c|}{$\begin{array}{l}\text { Do you have any physical limitations that } \\
\text { make riding a standard bicycle difficult for } \\
\text { you? }(n=1,623)\end{array}$}} \\
\hline Black or African American & 1.3 & & \\
\hline White or Caucasian & 85.4 & & \\
\hline Hispanic or Latino/a & 2.3 & Yes & 28.7 \\
\hline Other & 2.4 & No & 69.7 \\
\hline Prefer not to say & 3.8 & I prefer not to answer & 1.7 \\
\hline
\end{tabular}

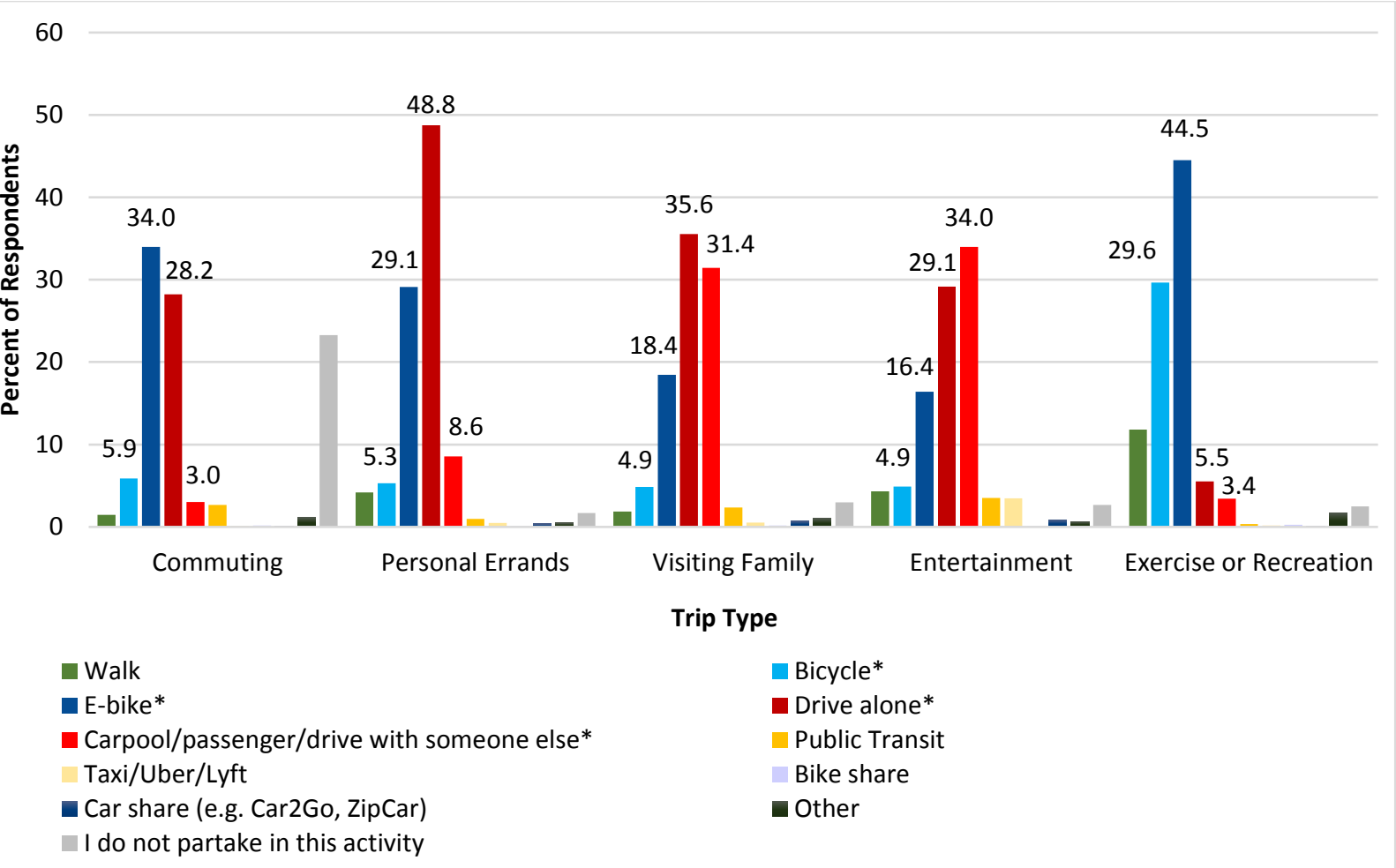

Figure 3.2: Mode Used for Various Trip Types Made by Respondents 
Table 3.3 provides reported characteristics about the respondents' e-bikes. The majority of respondents bought their e-bike fully assembled (78.7\%) rather than converting a standard bicycle (21.3\%). This finding contrasts with the 2013 survey, where only 48\% purchased fully assembled e-bikes. Of those that converted, 58.3\% used an existing bicycle and $41.7 \%$ used a newly bought bicycle. Most of the purchases were made at specialty e-bike shops (37.1\%) or online (35.6\%) within the past three years (e-bikes bought in 2015 and later account for 81.1\%). The most popular designs among the respondents were classified as "standard" e-bikes (39.5\%) and mountain bikes (27.8\%). Cargo bikes, including longtails, account for approximately 12\% of the reported e-bikes and were highly valued by many respondents in the open-ended responses, as one respondent stated: "My current e-bike is a cargo bike. I can carry passengers and cargo on it that I could not carry on my regular bike. I can also take multiple trips and longer trips that I would not take on a regular bike” (anonymous respondent). Over 50\% of the respondents' ebikes reported that the top assisted speed of their e-bike was $20 \mathrm{mph}$ (32 km/hr). It is important to note that speed-pedelecs, e-bikes with a top speed $28 \mathrm{mph}$ (45 km/hour), were reportedly owned by approximately $20 \%$ of the respondents. Furthermore, the respondents were asked what percent of time they operate their e-bike at different power settings, and the mean percentages were as follows: maximum power setting was $29.2 \%$, medium power setting was $32.0 \%$, lowest power setting was $29.8 \%$, and without power was $9.1 \%$. The results show that satisfaction with the e-bikes is very high, whereas less than $5 \%$ where neutral or unsatisfied to some degree with their e-bike.

Table 3.3: E-bike Characteristics

\begin{tabular}{|c|c|c|c|}
\hline Purchase or convert $(n=1,784)$ & $\begin{array}{c}\text { Value } \\
\text { (\%) }\end{array}$ & Converted Old or New Bicycle $(\mathrm{n}=386)$ & $\begin{array}{c}\begin{array}{c}\text { Value } \\
(\%)\end{array}\end{array}$ \\
\hline I purchased an e-bike & 78.7 & I used an existing bicycle & 58.3 \\
\hline I converted a standard bicycle & 21.3 & I bought a new bicycle & 41.7 \\
\hline Year Bought $(\mathrm{n}=1,763)$ & & Type of E-bike $(n=1,796)$ & \\
\hline 2015 or later & 81.1 & Standard e-bike & 39.5 \\
\hline 2011-2015 & 15.4 & Mountain bike & 27.8 \\
\hline 2010 or before & 3.5 & Step-thru & 12.1 \\
\hline Where Purchased $(\mathrm{n}=1,791)$ & & Cargo & 11.8 \\
\hline Standard bicycle shop that has some e-bikes & 18.6 & Folding & 2.1 \\
\hline Specialty e-bike shop & 37.1 & trike & 3.8 \\
\hline Specialty electric vehicle shop & 1.8 & Scooter & 0.3 \\
\hline Big box store, superstore, outdoor retailers & 1.5 & E-scooter pedals & 0.4 \\
\hline Online & 35.6 & Other & 2.1 \\
\hline Other & 5.3 & Satisfaction with E-bike $(n=1,790)$ & \\
\hline Top Speed $(\mathrm{n}=1,783)$ & & Very unsatisfied or unsatisfied & 1.8 \\
\hline $15.5 \mathrm{mph}$ or $25 \mathrm{~km} / \mathrm{hour}$ & 5.8 & Neutral & 2.7 \\
\hline $18 \mathrm{mph}$ or $28 \mathrm{~km} / \mathrm{hour}$ & 6.8 & Very satisfied or satisfied & 95.5 \\
\hline $20 \mathrm{mph}$ or $32 \mathrm{~km} / \mathrm{hour}$ & 55.1 & & \\
\hline $28 \mathrm{mph}$ or $45 \mathrm{~km} /$ hour & 20.1 & & \\
\hline Greater than $28 \mathrm{mph}$ or $45 \mathrm{~km} / \mathrm{hour}$ & 7.2 & & \\
\hline I do not know & 4.9 & & \\
\hline
\end{tabular}

Before purchasing their e-bike, 65\% of the respondents were at least somewhat familiar with ebikes. When asked where they got information about the different types of e-bikes and conversion options available, respondents received information from the internet (49\%), retailers 
(22\%), or a test ride event (11\%) (Table 3.4). Figure 3.3 shows to what degree different factors were considered when purchasing an e-bike. The most seriously considered factors were bike type or style (68\%) and battery range (60\%). The least consideration went into the brand (27\% did not consider this) and motor technology (i.e., pedal-assist or throttle; $22 \%$ did not consider this) of the e-bike.

Table 3.4: Prior Knowledge about E-bikes

\begin{tabular}{|c|c|c|c|}
\hline \multicolumn{2}{|c|}{$\begin{array}{l}\text { Where did you get information about the types of e- } \\
\text { bikes/conversion options available? }(n=2,131)\end{array}$} & \multicolumn{2}{|c|}{$\begin{array}{l}\text { How familiar were you with e-bikes before } \\
\text { you purchased yours? }(n=1,634)\end{array}$} \\
\hline & Value (\%) & & Value (\%) \\
\hline Magazines & 4.7 & Very familiar & 20.9 \\
\hline Internet/websites/blogs & 48.7 & Somewhat familiar & 44.0 \\
\hline Visited retailers & 22.0 & Somewhat unfamiliar & 19.7 \\
\hline $\begin{array}{l}\text { Family/friend/colleague who had } \\
\text { an e-bike }\end{array}$ & 9.8 & Very unfamiliar & 15.3 \\
\hline Test ride event & 11.0 & & \\
\hline Other (Please specify) & 3.7 & & \\
\hline
\end{tabular}

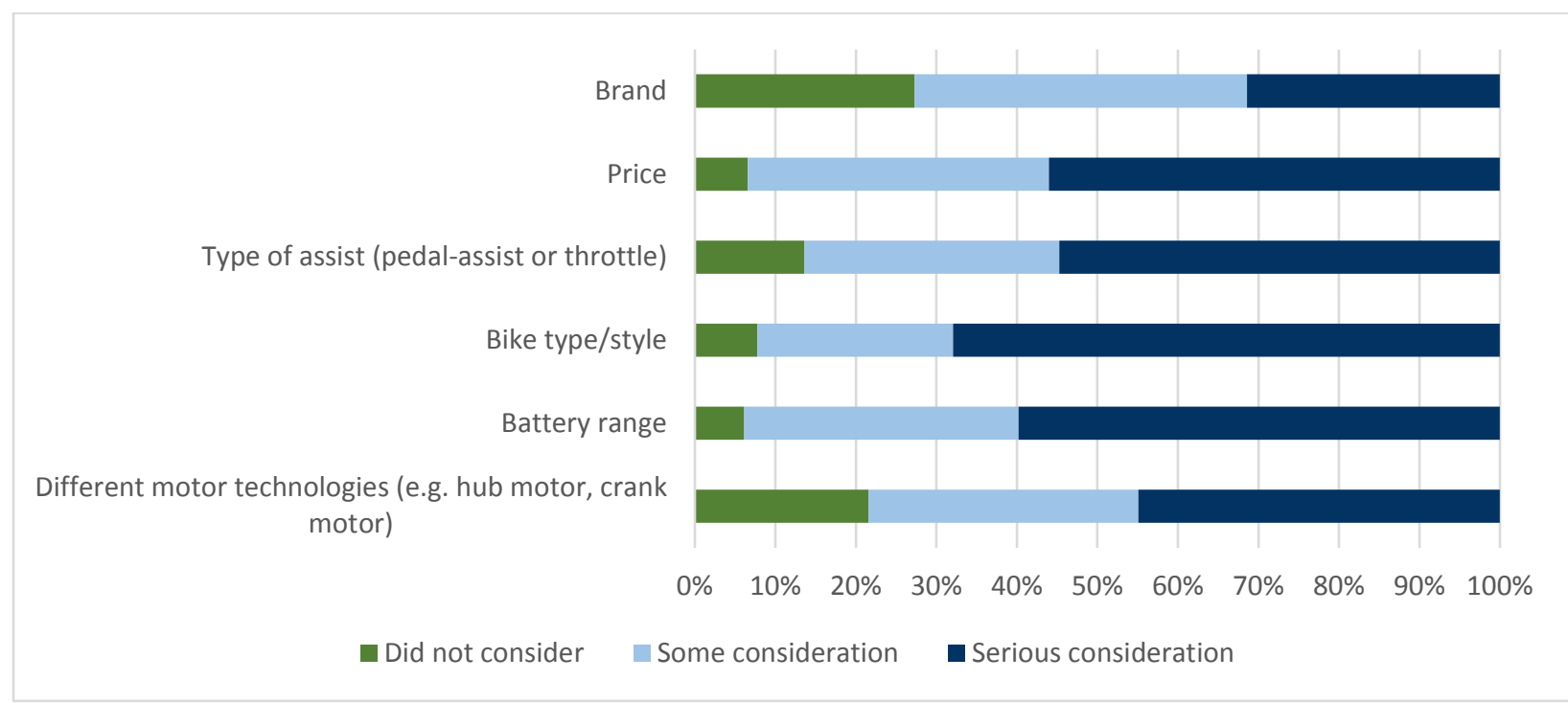

Figure 3.3: Important Considerations at Time of Purchase

Table 3.5 contains information regarding the frequency and type of service demanded by respondents' e-bikes. More than two-thirds of the respondents (70\%) have not had to have their e-bike serviced for an issue related to the battery, motor or electronic system. Approximately 7\% have had their e-bike serviced three or more times. The most common issues that required service were related to the electronics or display (37\%), the battery (28\%) and the motor (21\%). When asked to describe any specific problems they have had with their e-bike respondents mentioned issues with functionality (e.g., motor cuts out and defective battery) and performance (e.g., insufficient power and weak brakes). Maintenance and upkeep of the bike were commonly cited disadvantages related to riding an e-bike, most notably the increased difficulty of changing the tube in the rear tire with a hub motor. E-bike users also expressed the challenge of finding a bike shop that could repair their e-bike and replace parts, "getting service and parts is hard, having to put up with [people] who think everyone should ride a non-motorized bike when 
they're not aware that there are people who physically can't use them” (anonymous respondent). Given the additional weight of the e-bike, worrying about the range of the battery was commonly expressed in open-ended responses. For example, one respondent stated, "Running out of power can be a concern, because the bike is very heavy and unpleasant to ride with no assistance, worse than my regular bike. Also, it's heavy to lift onto public transport” (anonymous respondent).

Table 3.5: E-bike Service

\begin{tabular}{lcclcc}
$\begin{array}{lcclc}\text { Number of times e-bike has } \\
\text { been serviced }\end{array}$ & $(\%)$ & & Part of the e-bike that was serviced & $(\%)$ \\
\cline { 1 - 2 } \cline { 5 - 6 } 2 & 14.6 & & Repairs to the electronics/display & 37.5 \\
2 & 7.3 & & Repairs to motor & 20.9 \\
3 & 3.3 & & Replace battery or battery issues & 27.9 \\
4 & 1.3 & & Bike-related issues & 7.5 \\
5 or more times & 3.3 & & Other (Please specify) & 6.2 \\
No service needed to date & 70.0 & & & \\
\hline
\end{tabular}

\subsection{BARRIERS TO BIKING MORE OFTEN}

Respondents were asked to report the top three factors that kept them from biking more often. They were able to choose from 11 prescribed options or check "Other" and provide an explanation. This question was answered by 1,755 respondents, although not all respondents ranked a total of three barriers. The most frequently reported barriers included hills (53.6\%), lengthy distances to desired destinations (40.3\%), and not liking to arrive at destinations sweaty (31.6\%). The former two barriers were also most frequently cited as the primary barrier; however, as a primary barrier, the latter was replaced by "None, I biked enough already." Physical ability, cargo limitations and weather conditions were also highly reported barriers (Figure 3.4). 


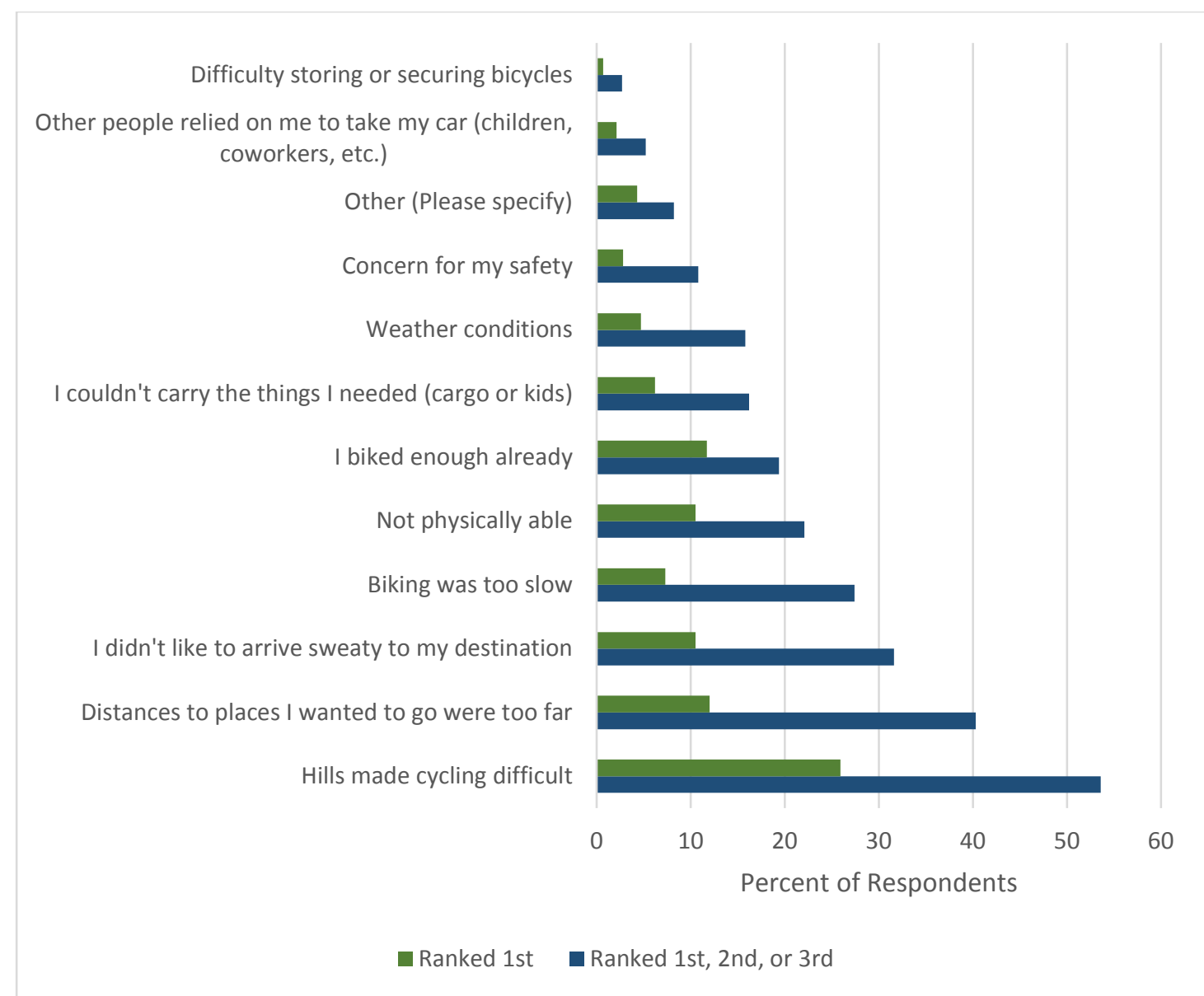

Figure 3.4: Important Barriers to Riding a Standard Bicycle

These results were disaggregated by gender, age and physical ability to illuminate any differences that may exist between groups (Table 3.6). The cutoff point for age was set at 55 years, this number was chosen for two reasons. First, previous studies have shown that adult bicycling habits tend to decline around this age. Second, separating the respondents at 55 years results in a fairly even split between younger and older adults, while if the retirement age was used, 65 years, the older respondents would represent less than $20 \%$ of the sample. The most pronounced differences between males and females were that females (64.8\%) were more likely to report hills as a barrier than males (49.9\%); and males were more likely to report that they did not like to arrive to their destination sweaty (34.1\%) and that biking was too slow (30.9\%) compared to females (26.2\% and $19.0 \%$, respectively). Notable group variation within age and physical ability categories were similar for multiple barriers. Younger respondents and those without a physical limitation were less likely to report that they were not physically able to ride, and more likely to cite not liking to arrive at their destination sweaty, not being able to carry the things they needed, and that biking was too slow. Additionally, those without a physical limitation (22.6\%) were more likely to report that there were no barriers and they biked enough already than their counterparts (11.9\%). These differences are further reinforced by the barriers selected as the primary factors respondents did not bike as often.

In addition to these prescribed barriers, "Other" was selected by 144 (8.2\%) of respondents. These respondents commonly cited the lack of safe bicycle infrastructure, their health status, not 
owning a bicycle, and having faster and less tiring alternatives as barriers to riding a bicycle more often. Throughout open-ended responses, e-bike users often expressed insufficient bicycle infrastructure as a significant barrier to riding more (for both standard bicycles and e-bikes), as one participant states, "I don't always have safe infrastructure to get where I need to go. [If that is the case] Then I drive” (anonymous respondent). Some of these barriers to riding a standard bicycle cannot be solved by switching to an e-bike; however, e-bikes can increase speed, reduce effort and perspiration, permit riding for those with physical limitations, extend feasible distances, and "flatten" hills, which can support an increase in bicycle commuting. A quote from one e-bike user expresses this quite well, "Before the e-bike I would normally only commute to work 2-3 days a week (because of the weight of my laptop, clothes, lunch, etc.). The extra weight, combined with the amount of elevation gain, would leave my legs too tired to commute more than that. However, I can now easily commute 5 days a week” (anonymous respondent).

Table 3.6: Barriers that Limited Utilitarian Riding

\begin{tabular}{|c|c|c|c|c|c|c|c|c|}
\hline & \multicolumn{8}{|c|}{ Ranked as an Important Barrier to Riding a Standard Bicycle } \\
\hline & Count & $(\%)$ & Male & Female & $<55$ & $\geq 55$ & $\begin{array}{l}\text { Physical } \\
\text { Limitation }\end{array}$ & $\begin{array}{c}\text { No } \\
\text { Physical } \\
\text { Limitation }\end{array}$ \\
\hline Hills made cycling difficult. & 940 & 53.6 & 49.4 & 64.4 & 49.6 & 58.4 & 57.4 & 51.4 \\
\hline $\begin{array}{l}\text { Distances to places I wanted to } \\
\text { go were too far. }\end{array}$ & 708 & 40.3 & 40.0 & 40.4 & 38.6 & 41.6 & 38.7 & 40.6 \\
\hline $\begin{array}{l}\text { I didn't like to arrive sweaty to } \\
\text { my destination. }\end{array}$ & 554 & 31.6 & 33.8 & 26.0 & 40.4 & 22.0 & 20.4 & 36.6 \\
\hline Biking was too slow. & 480 & 27.4 & 30.5 & 18.9 & 32.2 & 21.5 & 20.0 & 30.2 \\
\hline Not physically able. & 388 & 22.1 & 20.4 & 24.3 & 10.1 & 35.1 & 54.4 & 8.0 \\
\hline I biked enough already. & 340 & 19.4 & 21.1 & 13.9 & 19.8 & 18.2 & 11.8 & 22.4 \\
\hline $\begin{array}{l}\text { I couldn't carry the things I } \\
\text { needed (cargo or kids). }\end{array}$ & 284 & 16.2 & 13.0 & 21.0 & 23.0 & 8.5 & 10.8 & 18.1 \\
\hline Weather conditions. & 277 & 15.8 & 15.5 & 17.4 & 15.6 & 16.2 & 13.3 & 17.3 \\
\hline Concern for my safety. & 189 & 10.8 & 10.0 & 13.7 & 9.6 & 12.5 & 13.5 & 10.2 \\
\hline Other (Please specify). & 144 & 8.2 & 8.4 & 7.6 & 7.5 & 9.2 & 9.5 & 7.7 \\
\hline $\begin{array}{l}\text { Other people relied on me to } \\
\text { take my car (children, } \\
\text { coworkers, etc.). }\end{array}$ & 92 & 5.2 & 4.8 & 6.7 & 8.1 & 2.1 & 3.0 & 6.2 \\
\hline $\begin{array}{l}\text { Difficulty storing or securing } \\
\text { bicycles. }\end{array}$ & 47 & 2.7 & 2.5 & 2.6 & 2.6 & 2.4 & 1.1 & 3.1 \\
\hline
\end{tabular}

Note: Bold Indicates significant differences between groups based on a chi-square test $(p<.05)$

\subsection{REASONS FOR BUYING OR CONVERTING TO AN E-BIKE}

Respondents were asked to select and rank the top three reasons they decided to buy an e-bike or convert a standard bike. They were given a list of 14 prescribed possibilities to choose from with the additional option of providing a reason not listed. A total of 1,787 respondents answered this question, although not all of them chose three options. Replacing car trips (27.7\%) and riding with less effort (27.7\%) were the most frequently cited reasons for buying or converting to an ebike. However, these items were only chosen as the primary reason by $8.9 \%$ and $8.3 \%$ of the 
respondents, respectively; living or working in a hilly area (11.2\%), recreational purposes (9.9\%), and having a medical condition that made riding a standard bicycle difficult (9.4\%) were all more likely to be chosen as the primary reason (Figure 3.5). Other important reasons included increasing fitness (25.3\%) and the desire to start cycling or cycling more (22.5\%). "To be able to keep up when riding with friends/family" and "To avoid traffic in my car" were chosen by the smallest percentage of respondents (excluding “Other”), 8.2\% and 6.2\%, respectively.

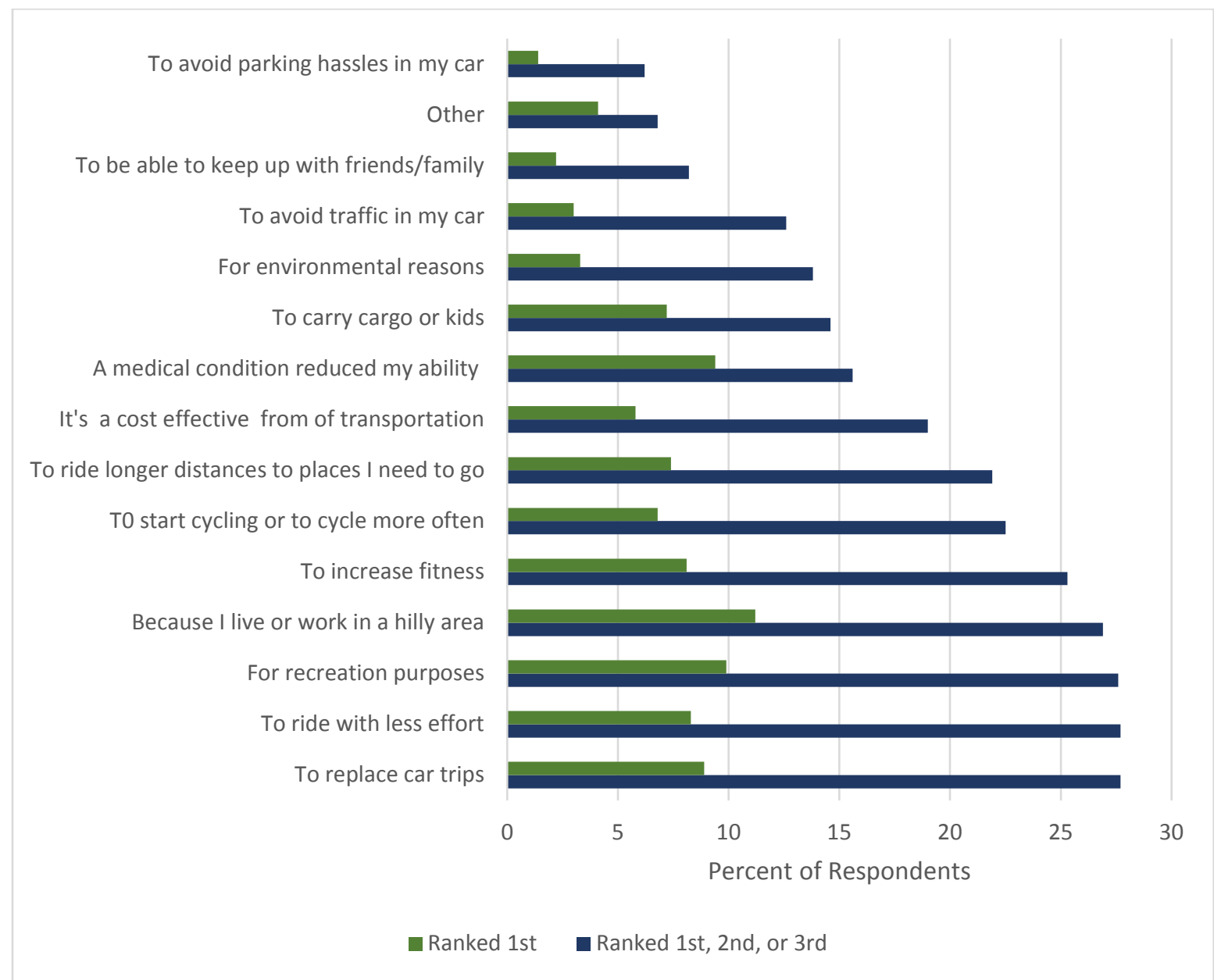

Figure 3.5: Important Reasons for Buying or Converting to an E-bike

To further examine these responses, respondents were split by gender, age and physical ability. Once disaggregated, differences between the groups were illuminated (Table 3.7). Females (38.6\%) were more likely to choose "Because I live or work in a hilly area" than males (23.0\%). They were also more likely to select "To carry cargo or kids" (21.3\%) and "To be able to keep up when riding with friends/family” (16.9\%) than their male counterparts (11.6\% and 5.3\%, respectively). Respondents' age seems have a substantial impact on their reasons for buying an e-bike or converting a standard bike. A greater percentage of older respondents (37.0\%) than younger respondents (19.1\%) indicated recreational reasons were an important deciding factor; additionally, they showcased a greater importance in increasing fitness (31.6\%) than younger adults (19.6\%). Conversely, younger adults (34.2\%) more frequently chose “To replace car trips" than the older respondents $(21.3 \%)$. There are also some prominent differences - similar to those 
found by age group - between those who reported having a physical limitation and those who did not. Unsurprisingly, a much higher percentage of respondents with a physical limitation (48.5\%) than without (2.4\%) selected "A medical condition reduced my ability to ride a standard bicycle" and they were less likely to choose replacing car trips (19.8\%) than adults without physical limitations (31.8\%).

In addition to these primary reasons, 121 respondents chose the "Other" category. Of these responses, where a description was provided, there were a few emergent themes. The enjoyment of riding an e-bike was the most popular reason for buying or converting to an e-bike outside of the prescribed choices; in addition, nearly a third of the respondents cited this as a main benefit of riding an e-bike (open-ended response). Other respondents stated that driving was not an option and the e-bike served as a viable alternative to a motor vehicle, and others valued the potential to save time and the self-reliance and freedom the e-bike could provide them.

Table 3.7: Motivations for Purchasing an E-bike

Ranked as an Import Reason for Buying or Converting to an E-bike

\begin{tabular}{|c|c|c|c|c|c|c|c|c|}
\hline & Count & $(\%)$ & Male & Female & $<55$ & $\geq 55$ & $\begin{array}{l}\text { Physical } \\
\text { limitation }\end{array}$ & $\begin{array}{c}\text { No Physical } \\
\text { limitation }\end{array}$ \\
\hline To replace car trips. & 495 & 27.7 & 28.7 & 26.5 & 34.2 & 21.3 & 19.8 & 31.8 \\
\hline To ride with less effort. & 495 & 27.7 & 28.2 & 27.5 & 24.0 & 32.5 & 26.5 & 28.6 \\
\hline For recreation purposes. & 494 & 27.6 & 29.2 & 22.6 & 19.1 & 36.9 & 28.8 & 26.9 \\
\hline $\begin{array}{l}\text { Because I live or work in a } \\
\text { hilly area. }\end{array}$ & 481 & 26.9 & 23.0 & 38.6 & 29.1 & 25.0 & 21.7 & 29.5 \\
\hline To increase fitness. & 452 & 25.3 & 26.8 & 20.8 & 19.6 & 31.6 & 29.7 & 22.9 \\
\hline $\begin{array}{l}\text { To start cycling or to cycle } \\
\text { more often. }\end{array}$ & 402 & 22.5 & 22.7 & 23.2 & 13.8 & 24.6 & 22.4 & 22.9 \\
\hline $\begin{array}{l}\text { To ride longer distances to } \\
\text { places I need to go. }\end{array}$ & 391 & 21.9 & 22.5 & 20.8 & 22.8 & 21.0 & 17.8 & 23.8 \\
\hline $\begin{array}{l}\text { It's a cost-effective form of } \\
\text { transportation. }\end{array}$ & 340 & 19.0 & 21.5 & 12.1 & 24.9 & 12.5 & 12.7 & 21.5 \\
\hline $\begin{array}{l}\text { A medical condition reduced } \\
\text { my ability. }\end{array}$ & 279 & 15.6 & 14.7 & 18.7 & 8.4 & 24.4 & 48.4 & 2.4 \\
\hline To carry cargo or kids. & 261 & 14.6 & 11.6 & 21.3 & 24.0 & 3.7 & 6.5 & 17.9 \\
\hline For environmental reasons. & 246 & 13.8 & 14.5 & 12.6 & 15.6 & 12.2 & 11.4 & 14.9 \\
\hline To avoid traffic in my car. & 226 & 12.6 & 13.8 & 9.1 & 16.7 & 7.0 & 5.6 & 15.6 \\
\hline $\begin{array}{l}\text { To be able to keep up with } \\
\text { friends/family. }\end{array}$ & 147 & 8.2 & 5.3 & 16.9 & 4.9 & 12.9 & 14.6 & 5.8 \\
\hline Other & 121 & 6.8 & 6.4 & 6.5 & 6.7 & 6.4 & 5.6 & 6.8 \\
\hline $\begin{array}{l}\text { To avoid parking hassles in my } \\
\text { car. }\end{array}$ & 111 & 6.2 & 6.5 & 5.9 & 8.5 & 3.6 & 4.5 & 7.0 \\
\hline
\end{tabular}

Note: Bold Indicates significant differences between groups based on a chi-square test $(p<.05)$ 


\subsection{E-BIKE USE}

The vast majority of e-bike users (93.4\%) rode a standard bicycle as an adult before owning an ebike. More than half of the respondents rode their standard bicycle as frequently as once a week; $30.3 \%$ of the respondents rode a standard bicycle weekly and $25.1 \%$ rode daily. After the purchase of an e-bike, the proportion of respondents riding a standard bicycle weekly or daily fell considerably. However, this decrease in frequent ridership of standard bicycles was met with an increase in total daily and weekly bicycling due to the proportion of respondents who frequently ride their e-bike (91.5\%). Although frequent ridership of a standard bicycle appears to decline after an individual purchases an e-bike, Figure 3.6 suggests that e-bikes can drastically increase rates of overall ridership. Of the $6.6 \%$ of people who said they had not ridden a standard bicycle as an adult, $93.5 \%$ of them now ride weekly or daily.

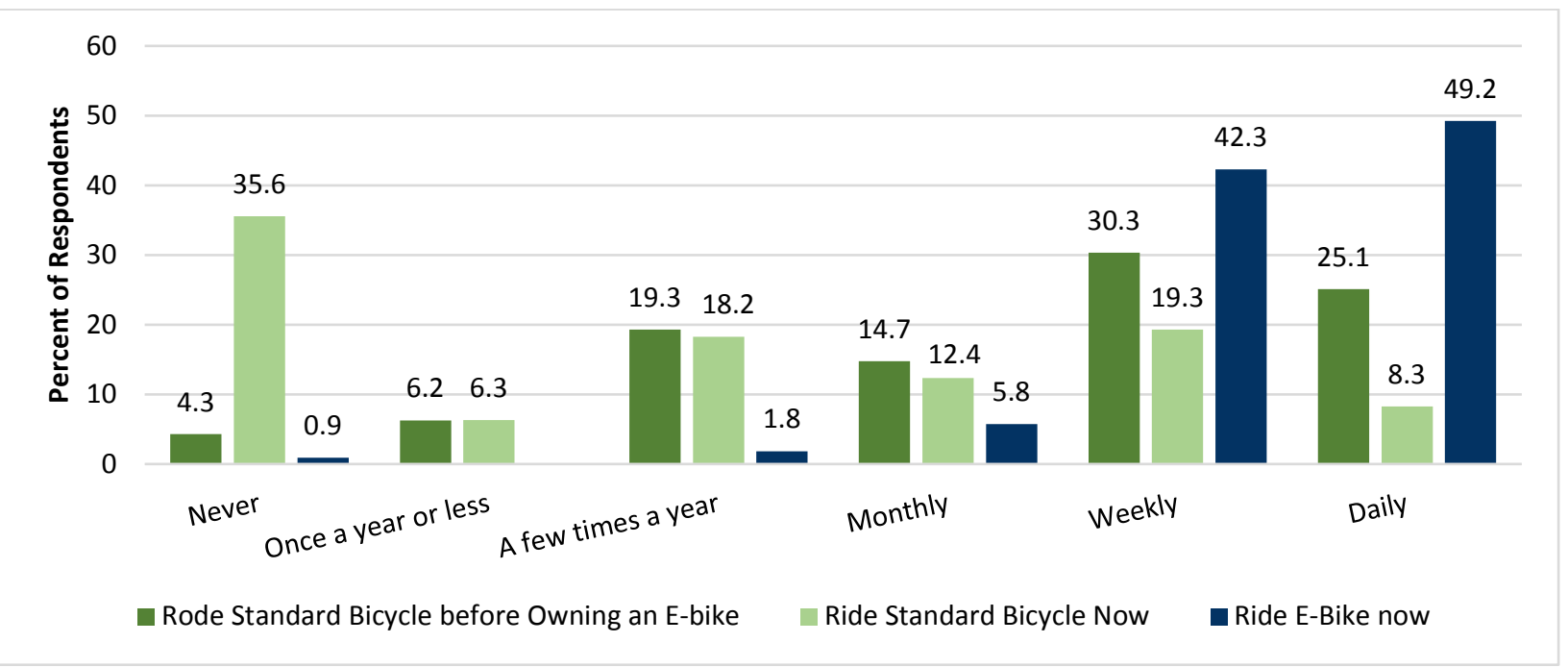

Figure 3.6: Bike Ridership Rates

Results also reveal that e-bikes are changing the purposes for which people utilize their bicycle as well as the routes used to get to destinations. Nearly $70 \%$ of the respondents stated that they ride for different purposes or to different destinations, or take different routes than they would on a standard bicycle. The respondents who provided an explanation commonly mentioned that they no longer had to avoid hilly areas and could tackle hills easily (30.5\%), it gave them the ability to ride farther (31.3\%), and they could use it for utilitarian purposes (17.8\%). The latter option was often accompanied by comments on quicker commute times, less effort needed and minimizing sweat upon arrival. As one respondent states, "I use my e-bike to commute because I don't need special clothing or shoes and I don't get as sweaty on hills or as tired from the ride. On my standard bike, I try to avoid hills as much as possible” (anonymous respondent).

Respondents were asked whether or not they agree with a variety of statements about general perceptions and experiences regarding riding their e-bike (Figure 3.7). Unsurprisingly, nearly all of the respondents (96.4\%) agreed or strongly agreed that they enjoyed their overall riding experience on their e-bike. The vast majority of respondents also agreed to some degree that they were able to travel farther, the speed and acceleration is exciting, they ride their e-bike more because it is more fun than a standard bicycle, and that they would rather cycle than drive a car. "My e-bike allows me to keep up with friends or family on bicycle rides" and "To ride the same 
trip by a standard bicycle, I would need to shower at my destination” were the least agreed with statements, $48.3 \%$ and 59.1\%, respectively. A notable portion of respondents (63.9\%) agreed or strongly agreed that they consciously conserve their battery power when riding their e-bike; in open-ended responses "range anxiety" was one of the most frequently cited disadvantages related to riding an e-bike.

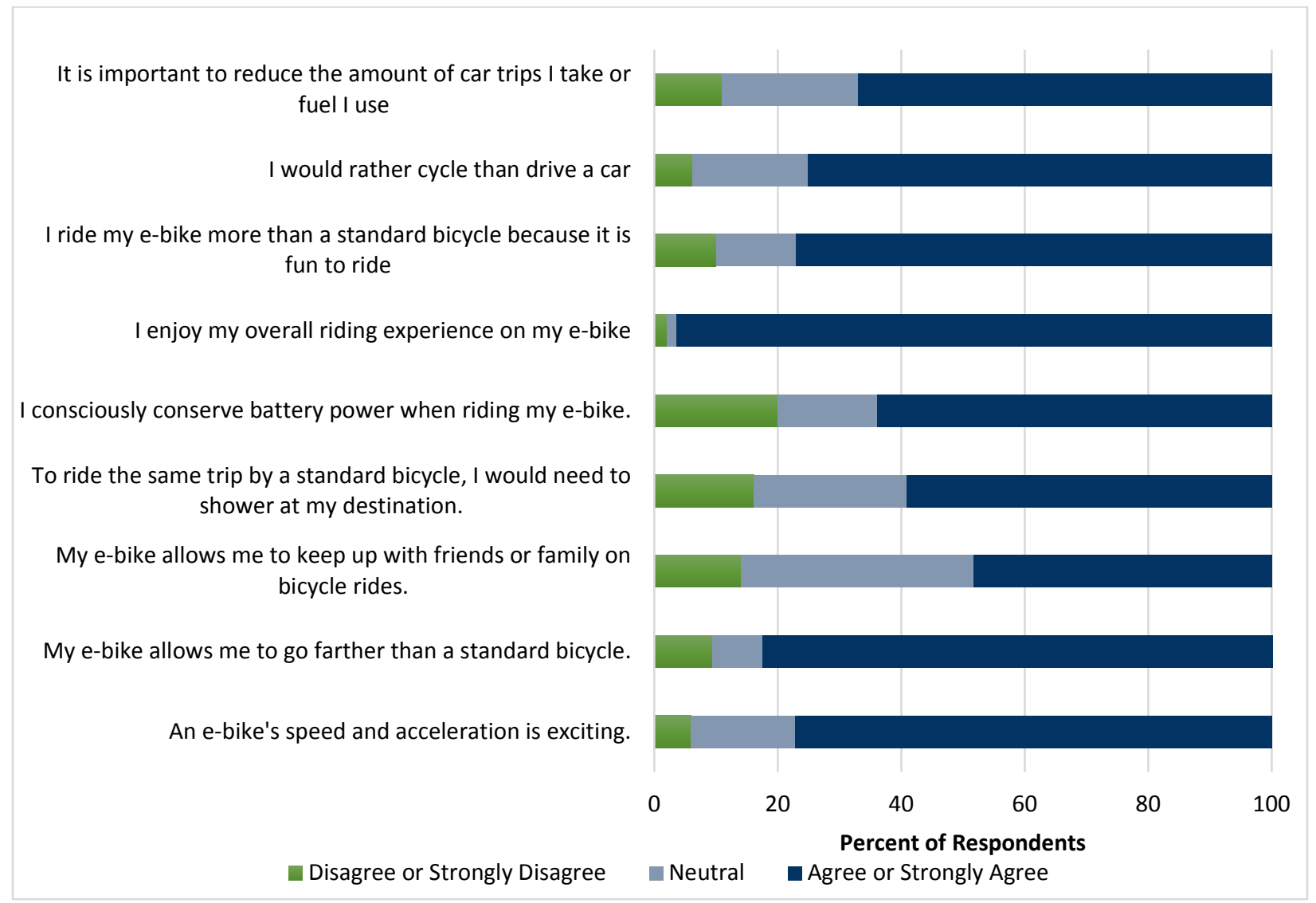

Figure 3.7: Attitudes of E-bike Users

These attitudinal responses were disaggregated by gender, age and physical ability; chi-squared results presented in Table 3.8 show significant differences in perceptions between groups. Males, younger respondents and those without a physical limitation where all less likely to agree or strongly agree that their e-bike allows them to keep up with friends or family on bicycle rides than their counterparts. Younger adults were more likely to agree to some degree that they would rather cycle than drive a car and that it is important to reduce the amount of car trips or fuel used than older adults. However, they were less likely to agree that they consciously conserve battery power and that they ride their e-bike more because it is more fun than a standard bicycle. Males more strongly agreed that is important to reduce car trips or fuel used than females. Lastly, respondents with a physical limitation were more likely to agree or strongly agree that their ebike allows them to travel farther distances than a standard bicycle when compared to those without a physical limitation. 
Table 3.8: Attitudes of E-bike Users by Respondent Characteristics

\begin{tabular}{|c|c|c|c|c|c|c|c|}
\hline & \multicolumn{7}{|c|}{ Percent of Respondents Who Agree or Strongly Agree by Group } \\
\hline & $\begin{array}{l}\text { All } \\
\text { respondents }\end{array}$ & Male & Female & $<55$ & $\geq 55$ & $\begin{array}{l}\text { Physical } \\
\text { limitation }\end{array}$ & $\begin{array}{c}\text { No } \\
\text { Physical } \\
\text { limitation }\end{array}$ \\
\hline $\begin{array}{l}\text { I enjoy my overall riding } \\
\text { experience on my e-bike. }\end{array}$ & 96.4 & 96.2 & 97.2 & 96.0 & 96.8 & 96.8 & 96.3 \\
\hline $\begin{array}{l}\text { My e-bike allows me to go } \\
\text { farther than a standard } \\
\text { bicycle. }\end{array}$ & 82.6 & 80.3 & 87.8 & 79.7 & 85.8 & 89.2 & 79.5 \\
\hline $\begin{array}{l}\text { An e-bike's speed and } \\
\text { acceleration are exciting. }\end{array}$ & 77.2 & 78.6 & 73.8 & 77.5 & 76.6 & 73.8 & 78.8 \\
\hline $\begin{array}{l}\text { I ride my e-bike more than a } \\
\text { standard bicycle because it } \\
\text { is fun to ride. }\end{array}$ & 77.1 & 77.5 & 76.4 & 71.8 & 82.7 & 83.1 & 74.3 \\
\hline $\begin{array}{l}\text { I would rather cycle than drive } \\
\text { a car. }\end{array}$ & 75.1 & 74.5 & 76.6 & 81.8 & 66.9 & 71.3 & 76.8 \\
\hline $\begin{array}{l}\text { It is important to reduce the } \\
\text { amount of car trips I take or } \\
\text { fuel I use. }\end{array}$ & 67.0 & 63.9 & 74.5 & 75.1 & 57.6 & 61.9 & 69.5 \\
\hline $\begin{array}{l}\text { I consciously conserve battery } \\
\text { power when riding my e- } \\
\text { bike. }\end{array}$ & 63.9 & 64.2 & 63.3 & 58.2 & 70.2 & 69.5 & 61.7 \\
\hline $\begin{array}{l}\text { To ride the same trip by a } \\
\text { standard bicycle, I would } \\
\text { need a shower at my } \\
\text { destination. }\end{array}$ & 59.1 & 61.3 & 54.8 & 62.0 & 55.9 & 56.9 & 60.1 \\
\hline $\begin{array}{l}\text { My e-bike allows me to keep } \\
\text { up with friends or family on } \\
\text { bicycle rides. }\end{array}$ & 48.3 & 42.9 & 59.8 & 40.5 & 56.2 & 67.0 & 40.1 \\
\hline
\end{tabular}

Respondents were also separated into groups to represent their bicycle ridership levels before owning an e-bike. Two types of cyclists were generated utilizing responses from two questions: "Before owning an e-bike, did you as an adult ride a standard bicycle?" and "Before you owned an e-bike, how often did you ride a standard bicycle?" Those who answered "no" to the former question and or reported they rode only a few times a year or less were classified as "seldom/non-cyclists" (30.5\%) and those who rode a standard bicycle monthly, weekly or daily were classified as "frequent cyclists" (69.5\%). Chi-squared tests indicate significant differences in perceptions of e-bike use between the types of cyclists (Table 3.9). "Seldom/non-cyclists" were significantly less likely to agree or strongly agree with the statements "it is important to reduce the amount of car trips I take or fuel I use" and "I would rather cycle than drive a car" than "frequent cyclists." These findings suggest "frequent cyclists" have a higher concern for replacing car trips and their use of their e-bike may be more catered to trips commonly made by car, such as errands and commuting. This topic will be explored further in the next section. On the other hand, "seldom/non-cyclists" were more likely to agree to some extent, when compared 
to their counterparts, that they ride their e-bike more than a standard bicycle because it is fun to ride, similar trips by standard bicycle would require a shower at their destination, their e-bike allows them to keep up with friends or family on bicycle rides, and they are able to travel farther than on a standard bicycle. The former representing differences in trip purpose (i.e., "seldom/non-cyclists"” perceptions of e-bike use are more highly geared towards fun and enjoyment) and the latter three represent differences in physical ability and skill (i.e., "frequent cyclists” can ride farther, faster and with less effort without the assist of the e-bike).

Table 3.9: Perceptions of E-bike Use by Cyclist Type

\begin{tabular}{|c|c|c|}
\hline & \multicolumn{2}{|c|}{$\begin{array}{c}\text { Percent of Respondents Who Agree or } \\
\text { Strongly Agree }\end{array}$} \\
\hline & Seldom/Non-cyclists & Frequent cyclists \\
\hline I enjoy my overall riding experience on my e-bike. & 95.8 & 96.7 \\
\hline $\begin{array}{l}\text { My e-bike allows me to go farther than a standard } \\
\text { bicycle. }\end{array}$ & 92.3 & 78.2 \\
\hline An e-bike’s speed and acceleration are exciting. & 78.0 & 76.7 \\
\hline $\begin{array}{l}\text { I ride my e-bike more than a standard bicycle because } \\
\text { it is fun to ride. }\end{array}$ & 89.1 & 71.7 \\
\hline I would rather cycle than drive a car. & 62.5 & 80.4 \\
\hline $\begin{array}{l}\text { It is important to reduce the amount of car trips I take } \\
\text { or fuel I use. }\end{array}$ & 56.0 & 71.5 \\
\hline $\begin{array}{l}\text { I consciously conserve battery power when riding my } \\
\text { e-bike. }\end{array}$ & 64.0 & 63.7 \\
\hline $\begin{array}{l}\text { To ride the same trip by a standard bicycle, I would } \\
\text { need a shower at my destination. }\end{array}$ & 65.9 & 56.3 \\
\hline $\begin{array}{l}\text { My e-bike allows me to keep up with friends or family } \\
\text { on bicycle rides. }\end{array}$ & 58.3 & 43.7 \\
\hline
\end{tabular}

Note: Bold Indicates significant differences between groups based on a chi-square test $(p<.05)$

\subsection{E-BIKE TRIPS}

As mentioned earlier, some respondents utilize their e-bike as their primary mode for a variety of different trips. Overall, exercise or recreation and commuting trips are the trip types most likely to be made primarily by e-bike. When disaggregated by age, gender and physical ability we see some substantial differences (Table 3.10). Most notably, older respondents and respondents with a physical limitation are far more likely to utilize e-bikes for recreational and exercise-based trips. On the other hand, younger respondents and those without a physical limitation are far more likely to use their e-bike as their primary mode for commuting purposes. This suggests that younger and more physically able e-bike users are more likely to be utilitarian riders, while older and physically limited e-bike users may find more value in their recreational purposes. 
Table 3.10: E-bike Used as Primary Mode by Respondent Characteristics

\begin{tabular}{|c|c|c|c|c|c|c|c|}
\hline & \multicolumn{7}{|c|}{$\begin{array}{c}\text { Percent of Respondents Who Selected E-bike as their Primary Mode by } \\
\text { Group }\end{array}$} \\
\hline & $\begin{array}{c}\text { All } \\
\text { Respondents }\end{array}$ & Male & Female & $<55$ & $\geq 55$ & $\begin{array}{l}\text { Physical } \\
\text { Limitation }\end{array}$ & $\begin{array}{c}\text { No } \\
\text { Physical } \\
\text { Limitation }\end{array}$ \\
\hline Commute & 34.0 & 35.3 & 31.5 & 45.9 & 20.5 & 23.4 & 38.5 \\
\hline Personal errands & 29.1 & 31.0 & 24.0 & 32.7 & 24.8 & 27.0 & 29.8 \\
\hline Visiting friends/family & 18.4 & 19.1 & 15.9 & 21.0 & 14.9 & 16.0 & 19.1 \\
\hline Entertainment & 16.4 & 16.1 & 17.0 & 19.3 & 12.9 & 16.2 & 16.7 \\
\hline Recreation or exercise & 44.5 & 45.8 & 41.8 & 38.0 & 52.2 & 55.0 & 40.2 \\
\hline
\end{tabular}

When these same results were disaggregated by cyclist type, significant differences were found between groups for each trip type (Table 3.11). Similar to older respondents and those with a physical limitation, "seldom/non-cyclists" were more likely to utilize their e-bike as their primary mode for recreation trips and less likely to use them for commute trips. Further examination shows that approximately a third of "seldom/non-cyclists" have a physical limitation and $53.7 \%$ are 55 years or older, suggesting that this group differentiates itself from the groups of older and physically limited respondents. However, they utilize their e-bike in a similar fashion when compared to their counterparts (less for utilitarian purposes and more for recreational purposes).

Table 3.11: E-bike Used as Primary Mode by Cyclist Type

\begin{tabular}{|c|c|c|}
\hline & \multicolumn{2}{|c|}{$\begin{array}{l}\text { Percent of Respondents Who Selected E-bike as their } \\
\text { Primary Mode }\end{array}$} \\
\hline & Seldom/Non-cyclists & Frequent cyclists \\
\hline Commute & 27.2 & 37.1 \\
\hline Personal errands & 19.3 & 33.2 \\
\hline Visiting friends/family & 11.6 & 21.1 \\
\hline Entertainment & 11.5 & 18.4 \\
\hline Recreation or exercise & 52.3 & 40.9 \\
\hline
\end{tabular}

Note: Bold Indicates significant differences between groups based on a chi-square test $(p<.05)$

Respondents were asked to report about the last three trips they made by e-bike, and report the purpose and distance of that trip as well as the mode that would have been taken if the e-bike was not used. Figure 3.8 shows that the most common trip types were recreation and exercise (35.6\%) and commute (32.7\%). Exercise and recreation and commute trips were also the longest trips on average. 


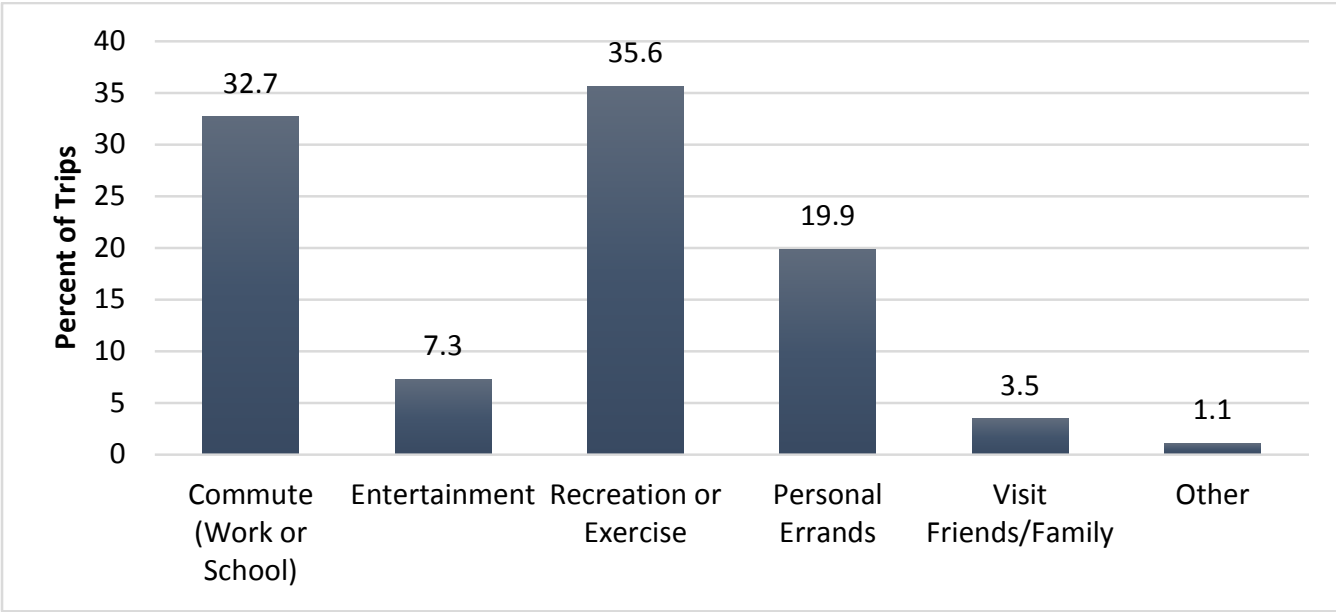

Figure 3.8: Percentages of Trip Types, Based on Respondents Three Most Recent E-bike Trips

Table 3.12 shows the percent of each trip type by the mode that would have been used in place of the e-bike and the mileage per trip for the different mode groups. The "Active transportation and Transit” group represents trips that would have been made by foot, standard bicycle, bikeshare, or public transit. The "Automobile" group represents trips that would have been made by singleoccupancy car, carpool, taxi, Uber or Lyft, and car share. "Would not have taken this trip" represents trips that otherwise would have not been made; nearly $90 \%$ of these trips were recreational or exercise trips. As expected, commuting trips (45.8\%) and personal errands (30.1\%) account for the majority of trips that would have been made by automobile if the e-bike was not used. The results show that e-bikes are also replacing a large number of trips that would have been made by active transportation modes or public transit, most of which are commute (39.8\%) and recreation or exercise trips (29.4\%). Furthermore, we are able to examine the average trip distance for each mode group. Trips that would not have been made were the longest trips, on average, which tend to be recreational. Interestingly, trips that would have been made by active transportation or transit are about the same average distance, 9.4 miles, as those that would have been made by automobile, 9.3 miles. E-bikes are reducing the number of trips made by automobile, which could provide numerous benefits to communities, including reduced traffic congestion and emissions and increased physical activity.

\section{Table 3.12: Trips Replaced by E-bike: Mode and Average Trip Length}

Percent of Trips by Mode that Would Have Been Used Instead of E-bike

\begin{tabular}{lcccc} 
& $\begin{array}{c}\text { Active Transportation } \\
\text { and Transit* }\end{array}$ & Automobile & $\begin{array}{c}\text { Would not Have } \\
\text { Taken this Trip }\end{array}$ & Other \\
\cline { 2 - 5 } Commute (work or school) & 39.8 & 45.8 & 1.1 & 36.2 \\
Entertainment & 8.1 & 8.9 & 3.5 & 5.8 \\
Recreation or exercise & 29.4 & 9.4 & 89.3 & 39.1 \\
Personal errands & 18.8 & 30.1 & 3.1 & 11.6 \\
Visit friends/family & 3.1 & 4.9 & 1.4 & 1.4 \\
Other & 0.8 & 0.8 & 987 & 5.8 \\
\hline n (\# of trips) & 1063 & 9.3 & 14.3 & 69 \\
\hline Mileage/Trip & 9.4 & 9.3 & 11.3 \\
\hline
\end{tabular}

*Includes all trips that would have been made by foot, standard bicycle, public transit, or bike-share 


\subsection{SAFETY}

Actual and perceived safety is known to have an impact on an individual's propensity to bicycle; this section explores the effects e-bikes may have on these factors. Most of the e-bike users (80\%; $n=1,315)$ have never experienced any crashes while riding their e-bike in the last two years. Of those respondents who have crashed, $19 \%(n=59)$ believe that their e-bike contributed in a significant way. When respondents were asked to think about their worst crash and who or what was involved, "Nothing - I lost control/fell over" and "Motor vehicle" were the most commonly selected options. More than half of the reported collisions resulted in no injury or mild injuries (scrapes and bruises) and approximately 15\% (n=49) required a trip to the hospital. Although accidents are occurring between e-bike users and other road users and roadside objects, a notable portion of respondents (38\%) felt that their e-bike has helped them to avoid a crash, citing both structural (i.e., stability, powerful brakes and good suspension) and functional (i.e., acceleration and speed) advantages of an e-bike.

While riding an e-bike, respondents very rarely feel in conflict with non-motorized commuters; nearly $75 \%$ of respondents responded with "never" or "rarely" when asked how often they feel in conflict with bicycles and pedestrians (Figure 3.9). However, 35.7\% of e-bike users often (“often" and "all the time”) feel in conflict with cars, and 20.5\% with buses and other large vehicles. These perceived conflicts line up with the respondents' reported crash data; accidents with motor vehicles were much more frequent (28.3\%) than those with another cyclist (3.3\%) and a pedestrian (2.3\%). Open-ended responses further support these findings; conflicts with motor vehicles was commonly cited when respondents were asked about any disadvantages or issues related to riding an e-bike. One e-bike user stated, "people do not know how to drive cars around bicyclist, many times cutting off and blocking bike paths with cars disregarding the safety of the cyclists. An e-bike helps with some of this as it can be safer to get out into the lane; however, there needs to be some awareness covered so that drivers are more aware of the laws regarding cyclist” (anonymous respondent). Although not very common, we see that some respondents occasionally feel in conflict with bicyclists and pedestrians. Some of these conflicts are also expressed through open-ended responses from e-bike users who mention "inattentive pedestrians" and negative comments such as “cheater" made by "lycra-clad cyclists" (anonymous respondents). 


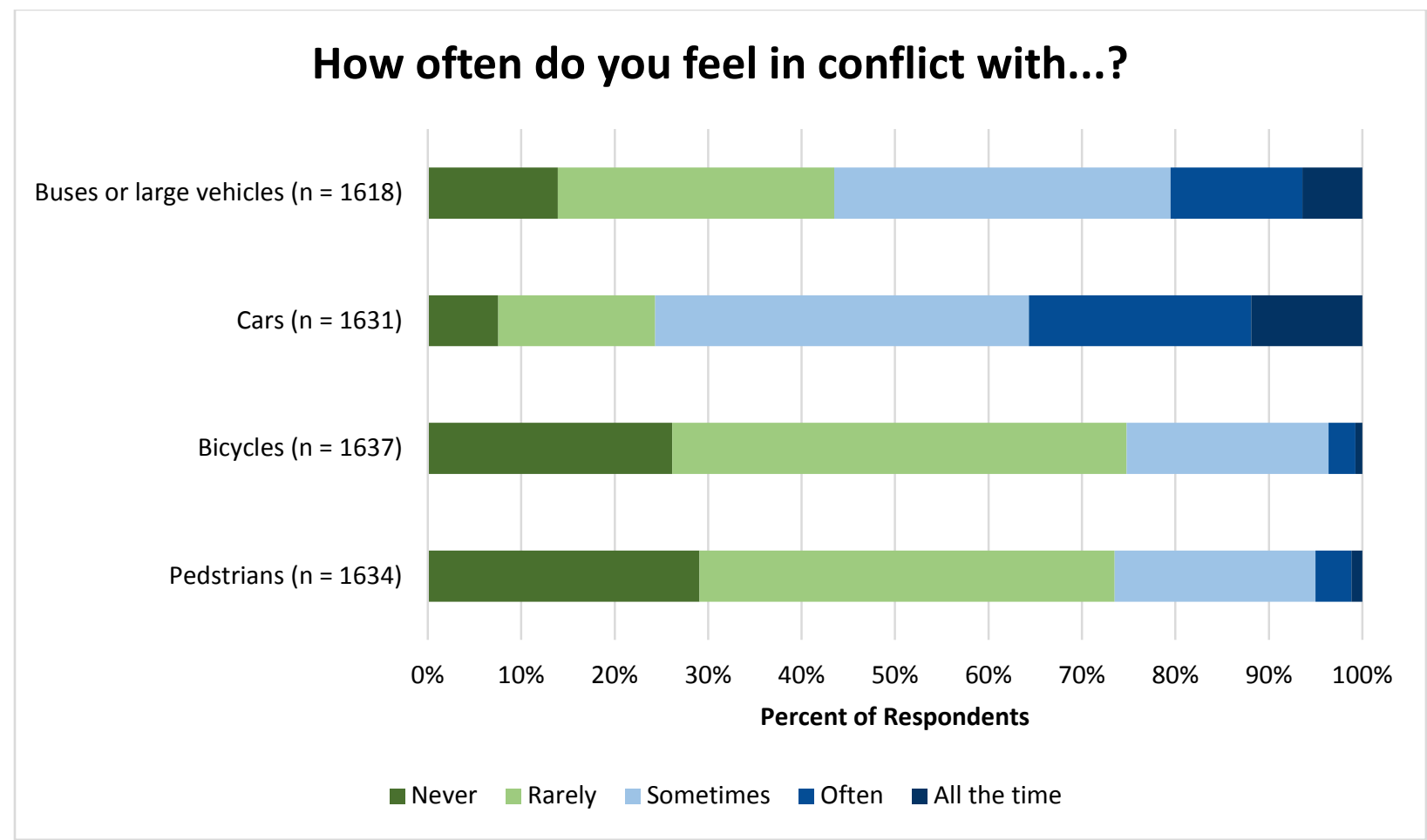

Figure 3.9: Perceived Conflict with Other Mode Types

Respondents were also asked if they agree or disagree with a variety of statements about perceived safety (Table 3.13). The results show that e-bike users tend to feel safer on their ebikes (78.3\% agreed or strongly agreed with "I feel safe riding an e-bike") than they do riding a standard bicycle (63.7\% agreed or strongly agreed with "I feel safe riding a standard bicycle"). In fact, many respondents believed that e-bikes increase their safety while riding. Commonly cited reasons include: keeping up with traffic, quicker acceleration through dangerous intersections, taking longer routes to avoid busy roads, not losing concentration due to physical exertion, increased visibility, and even accelerating away from unsafe social situations (openended responses). Approximately $40 \%$ of the respondents felt that other road users misjudged their speed. According to open-ended responses regarding negative experiences had while riding, some e-bike users feel at risk when drivers misjudge their speed, because it can result in dangerous situations where the driver thinks it is safe to make a turn or change lanes in front of the e-bike. Interestingly, $68.5 \%$ of respondents agree or strongly agree that they go faster than other cyclists, while $81.6 \%$ agree or strongly agree that, on average, they go faster than they would on a standard bicycle. In regards to safety, the speed of the e-bike is a more complicated aspect. Some respondents feel that the faster speeds make riding more dangerous (i.e., decreases reaction time, easier to lose control and exceeding comfortable speeds), and others feel that it permits safer riding (i.e., keeping up with traffic and avoiding dangerous situations). 
Table 3.13: Perceptions of Safety by Respondent Characteristics

\begin{tabular}{|c|c|c|c|c|}
\hline \multirow[b]{2}{*}{ Do you agree with the following statements? } & \multicolumn{4}{|c|}{ Percent of Respondents by Group } \\
\hline & $\begin{array}{c}\text { Disagree or } \\
\text { Strongly Disagree }\end{array}$ & Neutral & $\begin{array}{c}\text { Agree or } \\
\text { Strongly Agree }\end{array}$ & $\mathrm{n}$ \\
\hline \multicolumn{5}{|l|}{ I feel safe riding an e-bike. } \\
\hline All respondents & 7.2 & 14.5 & 78.3 & 1647 \\
\hline $\begin{array}{l}\text { Male } \\
\text { Female }\end{array}$ & $\begin{array}{l}7.6 \\
6.3\end{array}$ & $\begin{array}{c}16.2 \\
9.8\end{array}$ & $\begin{array}{l}76.2 \\
83.9\end{array}$ & $\begin{array}{c}1138 \\
461\end{array}$ \\
\hline $\begin{array}{l}<55 \text { years of age } \\
\geq 55 \text { years of age }\end{array}$ & $\begin{array}{l}6.4 \\
8.2\end{array}$ & $\begin{array}{l}11.6 \\
17.2\end{array}$ & $\begin{array}{l}82.0 \\
74.6\end{array}$ & $\begin{array}{l}844 \\
752\end{array}$ \\
\hline Respondents with a physical limitation & 7.8 & 17.2 & 75.0 & 464 \\
\hline Respondents without a physical limitation & 7.0 & 13.2 & 79.8 & 1130 \\
\hline \multicolumn{5}{|l|}{ I feel safe riding a standard bicycle. } \\
\hline All respondents & 14.9 & 21.4 & 63.7 & 1641 \\
\hline $\begin{array}{l}\text { Male } \\
\text { Female }\end{array}$ & $\begin{array}{l}15.0 \\
14.4\end{array}$ & $\begin{array}{l}22.3 \\
18.8\end{array}$ & $\begin{array}{l}62.7 \\
66.8\end{array}$ & $\begin{array}{c}1135 \\
458\end{array}$ \\
\hline$<55$ years of age & 12.3 & 18.0 & 69.6 & 843 \\
\hline$\geq 55$ years of age & 17.4 & 24.8 & 57.8 & 747 \\
\hline Respondents with a physical limitation & 22.0 & 24.8 & 53.2 & 459 \\
\hline Respondents without a physical limitation & 11.7 & 19.8 & 68.5 & 1129 \\
\hline \multicolumn{5}{|c|}{ On my e-bike, other road users misjudge my speed. } \\
\hline All respondents & 22.4 & 38.8 & 38.8 & 1644 \\
\hline Male & 21.8 & 37.6 & 40.6 & 1136 \\
\hline Female & 23.9 & 42.3 & 33.8 & 461 \\
\hline$<55$ years of age & 21.1 & 34.1 & 44.9 & 845 \\
\hline$\geq 55$ years of age & 23.9 & 45.0 & 31.1 & 749 \\
\hline Respondents with a physical limitation & 24.1 & 41.6 & 34.3 & 461 \\
\hline Respondents without a physical limitation & 21.9 & 37.4 & 40.7 & 1130 \\
\hline \multicolumn{5}{|c|}{ On my e-bike, I feel like I go faster than other cyclists. } \\
\hline All respondents & 12.6 & 19.0 & 68.5 & 1646 \\
\hline Male & 9.9 & 18.1 & 71.9 & 1137 \\
\hline Female & 19.3 & 20.4 & 60.3 & 461 \\
\hline$<55$ years of age & 11.5 & 14.1 & 74.4 & 845 \\
\hline$\geq 55$ years of age & 13.8 & 24.6 & 61.5 & 751 \\
\hline Respondents with a physical limitation & 17.2 & 27.2 & 55.6 & 464 \\
\hline Respondents without a physical limitation & 10.7 & 15.2 & 74.1 & 1130 \\
\hline \multicolumn{5}{|c|}{ On average, I ride faster than I would on a standard bicycle. } \\
\hline All respondents & 9.7 & 8.8 & 81.6 & 1645 \\
\hline $\begin{array}{l}\text { Male } \\
\text { Female }\end{array}$ & $\begin{array}{l}9.5 \\
9.8\end{array}$ & $\begin{array}{l}9.1 \\
8.2\end{array}$ & $\begin{array}{l}81.4 \\
82.0\end{array}$ & $\begin{array}{c}1136 \\
461\end{array}$ \\
\hline $\begin{array}{l}<55 \text { years of age } \\
\geq 55 \text { years of age }\end{array}$ & $\begin{array}{c}9.2 \\
10.3\end{array}$ & $\begin{array}{l}8.5 \\
8.7\end{array}$ & $\begin{array}{l}82.2 \\
81.1\end{array}$ & $\begin{array}{l}844 \\
750\end{array}$ \\
\hline Respondents with a physical limitation & 9.7 & 9.5 & 80.8 & 464 \\
\hline Respondents without a physical limitation & 9.5 & 8.4 & 82.1 & 1129 \\
\hline
\end{tabular}

Note: Bold Indicates significant differences between groups based on a chi-square test $(p<.05)$ 
When disaggregated by age, gender and physical ability, a few notable differences appeared between groups (Table 3.13). When compared to their counterparts, male respondents, younger respondents and respondents without a physical limitation were all more likely to agree or strongly agree that they feel like they go faster than other cyclists on their e-bike. Younger e-bike users were more likely to agree or strongly agree that they feel safe when riding an e-bike and a standard bicycle than older e-bike users, but less likely to agree or strongly agree that other road users misjudge their speed. Lastly, respondents with a physical limitation were less likely to agree to some degree than respondents without a physical limitation that they feel safe riding a standard bicycle.

"Seldom/non-cyclists" and "frequent cyclists" had relatively similar attitudes towards the statements regarding safety (Table 3.14). The only significant difference was between their perceived difference riding a standard bicycle. Approximately $70 \%$ of the "frequent cyclists" agreed or strongly agreed they feel safe riding a standard bicycle, while this proportion was less than half for the "seldom/non-cyclists." Perceived safety is a key determinant of a person's propensity to ride, so it makes sense those who feel less safe riding a standard bicycle are also those who ride less frequently. These results suggest that e-bikes may enhance perceived safety for those who do not feel comfortable on a standard bicycle.

Table 3.14: Perceived Safety by Cyclist Type

\begin{tabular}{lcc}
\hline & \multicolumn{2}{c}{$\begin{array}{c}\text { Percent of Respondents Who Agree } \\
\text { or Strongly Agree }\end{array}$} \\
\cline { 2 - 3 } & $\begin{array}{c}\text { Seldom/Non- } \\
\text { cyclists }\end{array}$ & Frequent cyclists \\
\hline I feel safe riding an e-bike. & 75.3 & 79.5 \\
I feel safe riding a standard bicycle. & $\mathbf{4 8 . 7}$ & $\mathbf{7 0 . 4}$ \\
On my e-bike, other road users misjudge my speed. & 36.5 & 39.9 \\
On my e-bike, I feel like I go faster than other cyclists. & 68.1 & 68.5 \\
On average, I ride faster than I would on a standard & 83.9 & 80.5 \\
bicycle. & & \\
\hline
\end{tabular}

Note: Bold Indicates significant differences between groups based on a chi-square test $(p<.05)$ 


\subsection{DISCUSSION}

This report sought to provide insight into the emerging realm of e-bike transportation through the fulfilment of four primary objectives. The first objective was to assess the demographic information provided by respondents to get a better understanding of who e-bike users are. Second, the report was to examine the motivations which influence an individual to purchase an e-bike with respect to the barriers of riding a standard bicycle. Third was to understand the types of trips e-bikes are being used for and their capacity to replace other modes of travel, especially automobiles. The final objective was to explore the safety implications of e-bikes and how e-bike users perceive safety while riding. Each of these objectives is related to the potential for e-bikes to tap latent demand for bicycle transportation and to increase frequency of riding and distances traveled by bicycle. Much of what is presented in this report is in accordance with findings from a previous survey on e-biking in North America (MacArthur et al., 2014). A larger sample size and a more robust questionnaire in the current study permitted a more complete understanding of the motivations and barriers of e-bike usage, and provided additional insight into not previously explored topics. This study also revealed findings that do not correspond with the previous survey, some of which are representative of the diffusion of e-bike technology, or the process by which e-bikes are adopted, accepted and embraced by the population. This report looks to present the results of the 2017 survey and compares results to the 2013 study when appropriate. The data of the two surveys are not statistically compared in this report but may be done in future analysis.

The larger sample size of the current study provides a clearer representation of the e-bike population, especially within minority groups such as females and individuals under 35 years of age. When compared to the 2013 study, younger adults and females are still a minority within the sample, yet their proportions are greater in this study. Given that neither survey utilized a random sample these proportions do not necessarily indicate an increase in ridership for these groups; however, the larger sample size inherently produces a more accurate approximation of their share in the e-bike population. Furthermore, the presented results are more strongly representative of the perspectives of these populations. In other words, our study supports previous findings that e-bike users are predominately male and the age distribution is skewed towards younger age groups, yet our sample proportions more strongly represent the population proportions and our results better represent their perspectives. The spatial distribution of respondents has provided data from more cities, states and provinces in addition to larger samples within all previously surveyed geographies within North America. One of the most apparent differences between these studies is related to the ways in which individuals are purchasing their e-bike. The previous study found that the bare majority of e-bike users had purchased a conversion kit for a standard bicycle rather than buying a fully assembled e-bike. Conversely, nearly $80 \%$ of the respondents in this study had purchased their e-bike fully assembled. This stark discrepancy could potentially be explained by improvements in technology, increasing number of distributors and model types, and increase in overall awareness.

The survey results presented in this study affirm previous findings that e-bikes have the capacity to mediate some of the barriers of riding a standard bicycle and can increase ridership, especially 
for populations who tend to bike less. Females, older adults and people with physical limitations are all less likely to ride a standard bicycle than their counterparts; these discrepancies manifest themselves in barriers such as safety, physical ability and medical conditions. Additional barriers not necessarily dependent on demographic characteristics such as long travel distances and the presences of hills also decrease the propensity to ride a standard bicycle for a given trip. However, e-bikes are able to minimize these barriers by providing additional support and comfort through electronic assist. The respondent comments provided below demonstrate how ebikes help alleviate the negative effects of these barriers:

- "My age (62) and the steep hills where I live, make standard biking impossible. My ebike has restored an activity I enjoyed when I was younger, even though then I still had to walk my bike up hill. I make an almost daily 2 mile shopping errand downhill and back up, and in good weather my e-bike substitutes for my truck."

- "I am 63 years old and have had 3 knee surgeries and cardiac bypass. Having an e-bike enables me to ride more often than I would on my regular bike. You need to understand how beneficial e-bikes are to us as we get older."

- "Due to my heart \& lung disease [my e-bike] is the only way I can ride again."

- "I have to travel a fair distance (24 miles round trip) with a lot of total elevation both directions (approximate 1,400 feet total). Riding the e-bike allows me to arrive without being exhausted and cuts the time of the ride by at least $20 \%$ - making it a viable option."

- "I can take 2-4 kids plus cargo, as a petite woman, and ride all over our city without worrying about making it home."

- "I live in the suburbs now, so the same errands are much longer distances. An e-bike makes it possible for me to continue to use a bike instead of a car."

- "Keeping up with city traffic is a safety benefit because of a lower speed differential.

- "I ride through several homeless camps on my eighteen mile trip. My e-bike gives me a sense of security knowing that I will have the energy/power to get out of the area if I feel threatened or fear for my safety."

In addition to getting more people to ride, results indicate that e-bikes can also increase how often people ride and can replace the use of modes that would have been used if not for the ebike. Approximately $7 \%$ of the respondents reported that they did not ride a bicycle as an adult before owning an e-bike, and $94 \%$ of them now ride their e-bike weekly or daily. Of those who did ride an e-bike as an adult, 59\% rode a standard bicycle weekly or daily, and now $91 \%$ of them ride their e-bike weekly or daily. Thus, those new to bicycling and regular bicyclists are taking more trips by bicycle than they had previously. Minimizing the barriers to choosing to bicycle for any given trip ultimately results in trip replacement of other modes, including motor vehicle trips, standard bicycle trips and public transit trips. Considering many state and city goals to increase physical activity and decrease vehicle miles traveled, $\mathrm{CO}_{2}$ emissions and traffic congestion, replacing the number of motor vehicle trips is a primary concern. Our results indicate that in the combined total of the respondents' last three trips, approximately 1,778 motor vehicle trips were replaced with an e-bike; the average distance for those trips was 9.3 miles. This represents an impressive decrease in vehicle miles traveled with an increase in the associated social, environmental and economic benefits. The following respondents' comments highlight both increasing rates of bicycling and mode replacement: 
- "I ride my e-bike consistently. I used to decide every morning whether I was biking in or taking transit, which was a small but regular mental burden. I no longer think about it. I usually ride quickly, but if I'm tired I can slow down and let the e-bike do more of the work. This is primarily a mental barrier."

- "A cargo bike with [a conversion kit] has allowed our family of 5 to live without a car for years. We can choose routes based on where we would like to go and safety without being as limited by hills, distance, or what we need to carry."

- "I just want to ride every day, I look for reasons to ride my e-bike, never did this before. E-bike replaced car for trips 20 miles or less round trip.”

- I am able to go places that are further without the need of public transportation (bike rack) or just bicycling. I am also able to explore areas outside of the public transportation map and beyond my workout comfort zone."

- "I choose my e-bike over public transportation every time now.... whereas with the standard bike, it would be weather dependent."

- "I have more energy, my knees don't hurt from hills, and I will stay out later because I can go faster and be safer in all areas. I can haul stuff and don't have to rent a HourCar (car share).”

- "Sold my SUV. E-bike is my only form of transportation now (unless I catch a ride with someone, or take an Uber or public transportation, but that's rare now).”

The additional power of the e-bike, when compared to a standard bicycle, facilitates differences in how and why people are riding their bicycle. The most commonly cited trip difference was that e-bikes permit longer trips. A lesser concern with physical exhaustion allows e-bike users to take longer routes to maximize safety (i.e., avoid high-traffic areas) and pleasure (i.e., routes with enjoyable views). On the other hand, not having to avoid hills or difficult terrain enables ebike users to take a more direct route, which can cut down commute times. Traveling with cargo and children also becomes easier, allowing e-bike users to make utilitarian trips not necessarily feasible on a standard bicycle. Lastly, many respondents indicated that their e-bike is used primarily for commute trips that they would not make with a standard bicycle because the distances were too far, it would take too long, and/or they don't like arriving to work sweaty or physically exhausted. The following comments capture how the respondents' e-bike trips differ from those made on a standard bicycle.

- "Could possibly go to a store farther from my house. Take different routes that might be more difficult when riding a regular bike. Take a more scenic route with the e-bike."

- "With the e-bike I take a longer but safer route to work and back. Or when I want to go to a particular grocery market (a round trip of 12 miles) I usually take my e-bike out for longer trips.”

- "I can take a less traveled (vehicular traffic) route that is VERY HILLY that I might not have with my conventional bike. This also makes the route safer (forgot to mention that above). I can ride a route that tends to have terrible headwinds and not struggle as much. I can go further and longer.” 
- "On the e-bike I am more likely to take the most direct route, like I would if driving a car. On a standard bike I am more likely to take the flattest or the safest route."

- "I'll ride my e-bike to get a week's worth of groceries that I would never do with my standard bike (though I liked to carry some cargo with it!). I bring my 40-pound 3-yearold on my e-bike, and I cannot do that with my standard bike."

- "My e-bike is better for commuting than my standard bike. It was difficult to go up hills and I arrived to work sweaty on my standard bike. Also I couldn't carry much on my standard bike. My e-bike is better for riding with a child or for going shopping."

- "I use my e-bike to commute because I don't need special clothing or shoes and I don't get as sweaty on hills or as tired from the ride."

As the previous study found, riding with less effort is one of the most important motivators for buying an e-bike. Similarly, the results suggest that different populations acknowledged different benefits of riding with less effort. Younger adults and those without a physical limitation valued being able to reduce car trips, haul more cargo, and get to their destination faster and without being sweaty. Older adults and those with physical limitations valued e-bikes for being less strenuous and even permitting riding after not being physically able to ride a standard bicycle. These values are reinforced in the differences between how these populations utilize their ebikes. Younger adults without physical limitations tend to utilize e-bikes for utilitarian purposes, while their counterparts tend to use them for recreation and exercise. Recreational and exercise trips have a lesser concern for timely arrival or physical appearance than commute or destination-oriented trips. The following comments demonstrate these discrepancies:

- "I live in a hilly area, so riding to work on my standard bike means I'm all sweaty when I arrive. The e-bike lets me take advantage of the fast commute to work without looking like I've been exercising when I get there."

- "It really helps me get out on the bike and not use my car. I don't feel like I am going to be a sweaty mess when I get where I am going and I can also get there faster if I need/want to engage full speed."

- "It allows me to cycle nearly year round which is terrific. I don't have to change clothes, I barely end up sweaty, and it shaves a bit of time off my commute. I can keep up with traffic where it matters (usually doesn't), and I don't worry when I load up my racks with 30-40 lbs. worth of stuff."

- "Because of my breathing problems I cannot ride a bike, but my e-bike allows me to get a little exercise and lots and lots of the pleasure of riding."

- "Physically unable to ride a standard bike. E-bike allows benefit of exercising muscles combined with joy of riding. It provides incredible freedom to people with disabilities and the fun of riding helps the motivation to get out in the fresh air and exercise!"

- "As a 64-year old retired person, it is a new and exciting experience to ride along the gorgeous dedicated bike path near the Sacramento River where I live. I don't give up and feel too exhausted trying to bike up the hills."

- "Yes an e-bike is a wonderful way to recuperate from an injury. It is easy on the back and the assist means biking is easy on arthritic knees." 
E-bikes increase the perceived safety of riding a bicycle for all segments of the population; the proportion of respondents who felt safe riding an e-bike (78\%) was greater than the proportion of respondents who felt safe riding a standard bicycle (64\%). Respondents were approximately eight times more likely to report that their e-bike has helped them avoid a crash than they were to report that the e-bike contributed to a crash. Crossing long intersections, speeding away from a dangerous situation, keeping up with the flow of traffic, and improved visibility were cited by respondents as ways the e-bike has increased their sense of safety. Despite feeling safer, many respondents often feel in conflict with cars, buses and other large vehicles. A smaller portion of e-bike users also reported that they experience conflict with pedestrians and bicycles. Inattentive users of the transportation network pose risks to e-bike users as they do to all other modes, especially those more vulnerable users. The following comments portray how e-bike users perceive safety and conflict:

- "I use the motor to get quickly (and I believe more safely) across intersections, whereas before, slowly getting across intersections sometimes would cause impatient drivers to do unsafe things like speed up past me, turn into me, etc."

- "I'm actually much more likely to follow all the rules of the road because I can easily accelerate and get back to speed while riding an e-bike.”

- "One of the safety advantages is that since I can ride faster, in traffic I often feel safer going closer to the flow of traffic in stop and start situations. Another advantage is with a motor, when stopped at a light I can "get off the line faster" thereby not feeling as vulnerable to a car behind you.”

- "I feel like I generally ride more safely on my e-bike. I also prefer the visibility I have on my e-bike in an upright position. The automatic lights on my e-bike are very convenient, so I am more visible and can ride easier in the dark."

- "People do not know how to drive cars around bicyclist, many times cutting off and blocking bike paths with cars disregarding the safety of the cyclists. An e-bike helps with some of this as it can be safer to get out into the lane however there needs to be some awareness covered so that drivers are more aware of the laws regarding cyclist.”

- "E-bikes share a hazard with standard bicycles - inattentive drivers or drivers who don't care and infrastructure that doesn't adequately address rider safety."

- "Sometimes road-users in cars and trucks pass me in unsafe areas. Probably misjudge my speed."

- "Standard cyclists are very upset when I pass them and try to out-ride me, then they cause dangerous situations. Road cyclists seem very antagonistic to e-bikes.”

By analyzing the same sub-groups of the population as the previous study, this report reaffirms known discrepancies in the perceptions and use of e-bikes. Perceived barriers, motivations to buy an e-bike, types of trips made by e-bike, and safety concerns tend to vary by the age, gender and physical ability of e-bike users. Disaggregating the respondents by their experience riding a standard bicycle prior to owning an e-bike provides novel insight into how those who are new to bicycling or rode infrequently perceive and use their e-bike. Similar to older adults and those with a physical limitation, e-bike users lacking previous bicycling experience are significantly less likely to feel safe on a standard bicycle and more likely use their e-bike for recreational and exercise trips rather than utilitarian trips than their counterparts. Yet more than a quarter of these 
respondents utilize their e-bike to commute. These findings provide evidence that e-bikes can be a viable mode of transportation and recreation for those without previous experience riding a bicycle, and could potentially function as a means to prepare or train one for riding a standard bicycle.

The results of this study suggest three ways in which e-bikes potentially serve to increase the total number of miles traveled by bicycle and the total number of trips made by bicycle. First, ebikes aid populations deterred from bicycling by physical limitations, topographic barriers and distance to cycle. Second, e-bikes support longer trips for both recreational and utilitarian pursuit. Finally, e-bikes can appeal to new audiences through enhancing perceived safety and the joy of riding. These benefits have the capacity to promote environmental (i.e., reduced emissions) and public health objectives (i.e., enhanced physical activity and increased time outside); however, they will not be met to their full potential in the absence of policies and regulations which support and protect the use of e-bikes. 



\subsection{REFERENCES}

Benjamin E. and Jamerson, F.E., Electric Bikes Worldwide Reports - Light Electric Vehicles / EV Technology. 2015.

Dill, J. \& Rose, G. E-bikes and transportation policy: Insights from early adopters Presented at the 90th Annual Meeting of the Transportation Research Board. Washington, DC, January 23-27, 2011.

Elliot Fishman \& Christopher Cherry. E-bikes in the Mainstream: Reviewing a Decade of Research, Transport Reviews, Volume 36, Issue 1, 2016, pp 72-91

Hamdouch, A., \& Depret, M. Policy integration strategy and the development of the 'green economy': foundations and implementation patterns. Journal of Environmental Planning and Management, 53(4), 473-490. June 2010.

Heinen, E., B. van Wee, and K. Maat. Commuting by Bicycle: An Overview of the Literature. Transport Reviews, Vol. 30, No. 1, 2010, pp. 59-96.9

Langford, B., C. Cherry, T. Yoon, S. Worley, and D. Smith, North America's First E- Bikeshare. Transportation Research Record: Journal of the Transportation Research Board, 2013. 2387: p. 120-128.

Langford, B.C., J. Chen, and C.R. Cherry, Risky riding: Naturalistic methods comparing safety behavior from conventional bicycle riders and electric bike riders. Accident Analysis \& Prevention, 2015. 82: p. 220-226.

Ling, Z., C.R. Cherry, J.H. MacArthur, and J.X. Weinert. "Differences of Cycling Experiences and Perceptions between E-Bike and Bicycle Users in the United States." Sustainability, 2017. 9(9): 1662.

MacArthur, J. and N. Kobel, Regulations of E-bikes in North America. National Institute for Transportation and Communities. NITC-RR-564. August 2014.

MacArthur, J., Jennifer Dill and Mark Person, "E-Bikes in North America: Results from an online survey," Transportation Research Record: Journal of the Transportation Research Board, TRR 2468 2014, pp. 123-130.

MacArthur, J., N. Kobel, J. Dill, and Z. Mumuni. Evaluation of an Electric Bike Pilot Project at Three Employment Campuses in Portland, OR. NITC-RR-564B. Portland, OR: Transportation Research and Education Center (TREC), 2017.

PeopleforBikes. Policies and Laws. http://peopleforbikes.org/our-work/e-bikes/policies-andlaws/ Accessed December 15, 2017. 
Popovich, N., E. Gordon, Z. Shao, Y. Xing, Y. Wang, and S. Handy, Experiences of electric bicycle users in the Sacramento, California area. Travel Behaviour and Society, 2014. 1(2): p. 37-44.

Pucher J., Jennifer Dill, and Susan Handy, "Infrastructure, Programs and Policies to Increase Cycling: An International Review," Preventive Medicine, Vol. 50(S1): S106-125, January 2010.

Pucher, J. \& Buehler, R. Analysis of bicycle trends and policies in large North American cities: Lessons for New York. Retrieved from http://www.utrc2.org/research/assets/176/BicycleBrief1.pdf, March 2011. 


\subsection{APPENDIX}

\section{SURVEY INSTRUMENT}

\section{Electric Bike Survey: Understanding Purchasing and Use}

Thank you for taking our survey!

The Transportation Research and Education Center at Portland State University is conducting a study of e-bike riders in the United States and Canada. We want to hear about your experiences purchasing and using your e-bike. In the last decade, electric bicycles (e-bikes) have become common in parts of Asia and Europe. In North America, e-bikes have not yet become a mainstream form of transportation. We would like to ask you some questions to learn more about the role e-bikes can play in our urban transportation systems.

The survey should take $\underline{15-20 \text { minutes. }}$

Thank you for taking the time to participate. Your responses are valuable and will help us understand more about how people use e-bikes.

At the end of the survey, you can enter a drawing for one of 10 \$50 Visa Gift Cards.

Statement of Informed Consent

Participants will share their e-bike experiences. Your participation is voluntary. You may opt out of the survey at any time. There are no expected physical or psychological impacts from taking part in the study. Your individual survey responses are anonymous and confidential. We will store the survey data on secured servers at Portland State University. It will not be possible to tell who said what in any reports. We do not anticipate any risk to you in answering the survey. No one will be able to identify you or your answers, and no one will know whether or not you participated in the study. Individuals from the Institutional Review Board may inspect these records. If the data is published, no individual information will be disclosed.

Portland State University does not release information about how any individual answers the survey and will not sell or give away the lists of respondents who participate in our research.

Any questions?

The Portland State University Institutional Review Board has reviewed this project. If you have any concerns about your rights in this study, please contact the PSU Office of Research Integrity at (503) 7252227 or email hsrrc@pdx.edu. If you have questions about the study itself, please contact John MacArthur by telephone at (503) 725-2866, by e-mail at macarthur@pdx.edu, or by mail at Transportation Research and Education Center (TREC), P.O. Box 751, Portland State University, Portland, OR 97207-0751.

Our research can only be successful with the generous help of people like you. We hope you will enjoy nswering our questions. Thank you for taking part in our e-bike survey! 
Do you agree to participate in this survey? By clicking "Accept”, you are consenting to participate in this survey. If you do not consent, please click "Decline” to navigate away from the survey.

\section{Accept (1)}

Decline (2)

Q146 In what country do you currently reside?

United States (1)

Canada (2)

Other (Please Specify) (3)

Q142 In which state do you currently reside?

Q132 Please enter your current 5-digit ZIP code.

Q147 In which province do you currently reside?

Q148 Please enter your postal code.

Q119 Section One: Your Electric Bicycle (E-bike) Questions in this section are about the e-bike you own or use regularly. If you have more than one e-bike, answer questions in this section about the ebike you use most often.

Q3 I own and/or often use an e-bike.

Yes (1)

No (2)

Q4 Did you purchase an e-bike or did you convert a standard bicycle?

I purchased an e-bike (1)

I converted a standard bicycle (2)

Q5 Did you convert an existing bicycle you owned or did you buy a new bicycle for the conversion?

I used an existing bicycle (1)

I bought a new bicycle (2) 
Q7 Where did you purchase your e-bike or e-bike conversion kit?

Standard bicycle shop that has some e-bikes (1)

Specialty e-bike shop (2)

Specialty electric vehicle shop (e.g. also sells scooters without pedals \& other bicycles) (3)

Big Box Store, Superstore, General Merchandise/Outdoor Retailers (4)

Online (5)

Other (Please specify) (6)

Q8 In what year did you purchase your e-bike or e-bike conversion kit?

Q9 Approximately much did your e-bike or e-bike conversion kit cost to purchase (enter a dollar value)?

Q15 What make/brand is your e-bike?

Q16 What model is your e-bike? If you do not know the model please briefly describe your e-bike's characteristics or features.

Q145 Which of these pictures most closely resembles your e-bike?

Image: Longtail (1)

Image: Hybrid2 (2)

Image: Step thru (3)

Image: E-bike mountain (4)

Image: E-cargo1 (5)

Image: E-scooter pedals (6)

Image: E-scooter (7)

My e-bike looks different than the other options (please briefly describe what your e-bike type or what it looks like): (8) 
Q127 What is the top assisted speed of your e-bike?

\section{$15.5 \mathrm{mph}$ or $25 \mathrm{~km} / \mathrm{hour}$ (1)}

$18 \mathrm{mph}$ or $28 \mathrm{~km} /$ hour (5)

$20 \mathrm{mph}$ or $32 \mathrm{~km} / \mathrm{hour}(2)$

$28 \mathrm{mph}$ or $45 \mathrm{~km} / \mathrm{hour}(3)$

Greater than $28 \mathrm{mph}$ or $45 \mathrm{~km} / \mathrm{hour}$ (6)

I do not know (4)

Q153 What percent of the time do you operate your e-bike on (Total needs to sum to $100 \%$ )... The maximum power setting :

The medium power setting :

The lowest power setting :

With the power disengaged :

Total :

Q59 How satisfied are you with your e-bike?

Very satisfied (2)

Satisfied (3)

Neutral (4)

Unsatisfied (5)

Very unsatisfied (6)

Q165

You answered that you are unsatisfied with your e-bike.

What would you want if you decided to purchase a new e-bike? 
Q19 Section Two: Purchasing your E-Bike Questions in this section relate to your decision to purchase your e-bike or convert a standard bicycle. For the purpose of this survey, a standard bicycle has no assist and is only propelled by the rider.

Q20 What were the top three reasons why you bought an e-bike or converted a standard bicycle? (Please select three)

To replace car trips (1)

Health - a medical condition reduced my ability to ride a standard bicycle (2)

Health - to increase fitness (3)

Because I live or work in a hilly area (4)

To ride with less effort (5)

To be able to keep up when riding with friends/family (6)

To carry cargo or kids (14)

Other (7)

It's a cost effective form of transportation (8)

To start cycling or to cycle more often (11)

To ride longer distances to places I need to go (12)

To avoid traffic in my car (20)

To avoid parking hassles in my car (21)

For environmental reasons (22)

For recreation purposes (9) 
Q129 Please rank your top-three reasons for buying an e-bike.

To replace car trips (1)

Health - a medical condition reduced my ability to ride a standard bicycle (2)

Health - to increase fitness (3)

Because I live or work in a hilly area (4)

To ride with less effort (5)

To be able to keep up when riding with friends/family (6)

To carry cargo or kids (7)

Other (8)

It's a cost effective form of transportation (9)

To start cycling or to cycle more often (10)

To ride longer distances to places I need to go (11)

To avoid traffic in my car (12)

To avoid parking hassles in my car (13)

For environmental reasons (14)

For recreation purposes (15)

Q22 Before purchasing your e-bike, what were the top-three factors (if any) that kept you from biking more often, either for commuting or for daily errands and trips (Please select three)?

Not physically able (1)

Distances to places I wanted to go were too far (2)

Hills made cycling difficult (3)

I couldn't carry the things I needed (cargo or kids) (4)

Other people relied on me to take my car (children, coworkers, etc.) (5)

Difficulty storing or securing bicycles (6)

Concern for my safety (7)

I didn't like to arrive sweaty to my destination (8)

Biking was too slow (9)

Weather conditions (10)

None - I biked enough already (11)

Other (Please specify) (12) 
Q130 Please rank the top-three factors that kept you from biking more often, either for commuting or for daily errands or trips.

Not physically able (1)

Distances to places I wanted to go were too far (2)

Hills made cycling difficult (3)

I couldn't carry the things I needed (cargo or kids) (4)

Other people relied on me to take my car (children, coworkers, etc.) (5)

Difficulty storing or securing bicycles (6)

Concern for my safety (7)

I didn't like to arrive sweaty to my destination (8)

Biking was too slow (9)

Weather conditions (10)

None - I biked enough already (11)

Other (Please specify) (12)

Q24 How familiar were you with e-bikes before you purchased yours?

Very familiar (1)

Somewhat familiar (2)

Somewhat unfamiliar (3)

Very unfamiliar (4) 


\section{Q121 Section Three: Travel}

This section is about your transportation habits and choices.

Q156

Think back on the last three times you used an e-bike...

How did you use it? How far did you go? If you had not taken your e-bike, how would you have traveled to your destination?

\begin{tabular}{|c|c|c|c|}
\hline & $\begin{array}{c}\text { Purpose of } \\
\text { Trip }\end{array}$ & Distance & $\begin{array}{l}\text { If you had not taken } \\
\text { your e-bike, how would } \\
\text { you have traveled to } \\
\text { your destination? }\end{array}$ \\
\hline & & $\begin{array}{l}\text { (Approximate } \\
\text { Miles) (1) }\end{array}$ & \\
\hline Ride 1 (1) & $\begin{array}{l}\nabla \text { Commute } \\
\text { (work or } \\
\text { school) (1) ... } \\
\text { Other (6) }\end{array}$ & & $\begin{array}{c}\boldsymbol{\nabla} \text { Walk (1) ... I would } \\
\text { not have taken this trip } \\
(10)\end{array}$ \\
\hline Ride 2 (2) & $\begin{array}{l}\nabla \text { Commute } \\
\text { (work or } \\
\text { school) (1) ... } \\
\text { Other (6) }\end{array}$ & & $\begin{array}{c}\boldsymbol{\nabla} \text { Walk (1) ... I would } \\
\text { not have taken this trip } \\
(10)\end{array}$ \\
\hline Ride 3 (3) & $\begin{array}{l}\nabla \text { Commute } \\
\text { (work or } \\
\text { school) (1) ... } \\
\text { Other (6) }\end{array}$ & & $\begin{array}{c}\nabla \text { Walk (1) ... I would } \\
\text { not have taken this trip } \\
(10)\end{array}$ \\
\hline
\end{tabular}

Q161 You indicated that your first ride was something other than what was listed. Briefly describe the purpose of that trip.

Q163 You indicated that the purpose of your second ride was something other than what was listed. Briefly, describe the purpose of that trip. 
Q164 You indicated that the purpose of your third ride was something other than what was listed. Briefly, describe the purpose of that trip.

Q149 Which mode do you primarily take to each of the listed activities?

\begin{tabular}{|c|c|c|c|c|c|c|c|c|c|c|}
\hline $\begin{array}{c}\text { I do } \\
\text { not } \\
\text { partak } \\
\text { e in } \\
\text { this } \\
\text { activit } \\
\text { y (1) }\end{array}$ & $\begin{array}{l}\text { Walk } \\
\text { (2) }\end{array}$ & $\begin{array}{l}\text { Bicycle } \\
\text { (3) }\end{array}$ & $\begin{array}{c}\text { E- } \\
\text { bike } \\
(4)\end{array}$ & $\begin{array}{c}\text { Driv } \\
\text { e } \\
\text { alon } \\
\text { e (5) }\end{array}$ & $\begin{array}{c}\text { Carpool } \\
\text { /passen } \\
\text { ger/driv } \\
\text { e with } \\
\text { someo } \\
\text { ne else } \\
\text { (6) }\end{array}$ & $\begin{array}{c}\text { Publi } \\
\text { c } \\
\text { Trans } \\
\text { it (7) }\end{array}$ & $\begin{array}{c}\text { Taxi/ } \\
\text { Uber/ } \\
\text { Lyft } \\
\text { (8) }\end{array}$ & $\begin{array}{l}\text { Bike } \\
\text { shar } \\
\text { e (9) }\end{array}$ & $\begin{array}{c}\text { Car } \\
\text { share } \\
(\text { e.g. } \\
\text { Car2G } \\
\text { o, } \\
\text { ZipCar) } \\
(10)\end{array}$ & $\begin{array}{c}\text { Othe } \\
r \\
(11)\end{array}$ \\
\hline
\end{tabular}

Commuting
(work and
school) (1)
Personal
errands (e.g.
groceries,
appointment
s) (2)
Visiting
family or
friends (3)
Entertainme
nt, dining
out, or
socializing
$(4)$
Exercise or
recreation
$(5)$

Q92 In a given week, what percentage of your trips are by...

Car :

(1)

E-bike :

(2)

Standard bicycle :

Public transportation :

Walk :

Other (please specify) :

Total :

Q39 About how far is your current daily commute (enter the approximate miles in one direction. Enter 0 if you don't have a daily commute to work or school)?

Q40 How long does your door-to-door commute to work or school take (Enter the number of minutes it takes you to get to work/school from your household. Enter 0 if you don't have a daily commute to work or school)? 
Q41 How often do you use your e-bike for the following activities?

\begin{tabular}{|c|c|c|c|c|c|c|}
\hline & $\begin{array}{l}\text { Daily } \\
\text { (1) }\end{array}$ & $\begin{array}{l}\text { Weekly } \\
\text { (2) }\end{array}$ & $\begin{array}{l}\text { Monthly } \\
\text { (3) }\end{array}$ & $\begin{array}{l}\text { A few } \\
\text { times a } \\
\text { year } \\
(4)\end{array}$ & $\begin{array}{l}\text { Once a } \\
\text { year or } \\
\text { less (5) }\end{array}$ & $\begin{array}{l}\text { Never } \\
(6)\end{array}$ \\
\hline $\begin{array}{l}\text { Commuting } \\
\text { (e.g. work, } \\
\text { school) (1) }\end{array}$ & & & & & & \\
\hline $\begin{array}{c}\text { Personal } \\
\text { errands (e.g. } \\
\text { groceries, } \\
\text { appointments) } \\
\text { (2) }\end{array}$ & & & & & & \\
\hline $\begin{array}{l}\text { Visiting family } \\
\text { or friends (3) }\end{array}$ & & & & & & \\
\hline $\begin{array}{l}\text { Entertainment, } \\
\text { dining out, or } \\
\text { socializing (4) }\end{array}$ & & & & & & \\
\hline $\begin{array}{l}\text { Exercise or } \\
\text { recreation (5) }\end{array}$ & & & & & & \\
\hline
\end{tabular}




\begin{tabular}{l|cccc} 
Strongly & $\begin{array}{c}\text { Disagree } \\
\text { Disagree } \\
(2)\end{array}$ & $\begin{array}{c}\text { Neutral } \\
(99)\end{array}$ & $\begin{array}{c}\text { Agree } \\
(6)\end{array}$ & $\begin{array}{c}\text { Strongly } \\
\text { agree (7) }\end{array}$ \\
\hline $\begin{array}{c}\text { An e-bike's speed and acceleration } \\
\text { is exciting. (1) }\end{array}$ \\
$\begin{array}{c}\text { My e-bike allows me to go farther } \\
\text { than a standard bicycle. (2) }\end{array}$ \\
$\begin{array}{c}\text { My e-bike allows me to keep up with } \\
\text { friends or family on bicycle rides. (6) }\end{array}$ \\
$\begin{array}{c}\text { To ride the same trip by a standard } \\
\text { bicycle, I would need to shower at } \\
\text { my destination. (8) }\end{array}$ \\
$\begin{array}{c}\text { I consciously conserve battery } \\
\text { power when riding my e-bike. (9) }\end{array}$ \\
$\begin{array}{c}\text { I enjoy my overall riding experience } \\
\text { on my e-bike (11) }\end{array}$ \\
$\begin{array}{c}\text { I ride my e-bike more than a } \\
\text { standard bicycle because it is fun to } \\
\text { ride (12) }\end{array}$
\end{tabular}

Q62 What are the main benefits to you of riding an e-bike?

Q63 What disadvantages or issues have you experienced related to riding an e-bike? 
Q122 Section Four: Safety

This section is about safety on your e-bike.

Q137 Do you agree with the following statements?

$\begin{array}{ccccc}\text { Strongly } & \text { Disagree } & \text { Neutral (99) } & \text { Agree } & \text { Strongly agree } \\ \text { Disagree } & \text { (2) } & & \text { (3) } & \text { (4) }\end{array}$

I feel safe riding an e-
bike. (1)
I feel safe riding a
standard bicycle. (2)
On my e-bike, other
road users misjudge my
speed. (5)
On my e-bike, I feel like
I go faster than other
cyclists (6)
On average, I ride
faster than I would on a
standard bicycle. (7)

Q67 How often do you feel in conflict with the following traffic types?

$\begin{array}{cccccc}\text { Never (1) } & \text { Rarely (2) } & \begin{array}{c}\text { Sometimes } \\ \text { (3) }\end{array} & \begin{array}{c}\text { Often } \\ \text { (4) }\end{array} & \begin{array}{c}\text { All the } \\ \text { time (5) }\end{array} & \begin{array}{c}\text { I don't } \\ \text { know }\end{array} \\ & & & & & \text { (99) }\end{array}$

\begin{tabular}{c|cccccc} 
Pedestrians (1) & 0 & 0 & 0 & 0 & 0 & 0 \\
Bicycles (2) & 0 & 0 & 0 & 0 & 0 \\
Cars (3) & 0 & 0 & 0 & 0 & 0 & 0 \\
$\begin{array}{l}\text { Bus or large } \\
\text { vehicles (4) }\end{array}$ & 0 & 0 & 0 & 0 & 0
\end{tabular}


Q68 Have you experienced any crashes while riding your e-bike in the last two years?

Yes - I've experienced one or more crashes. (1)

No (3)

Q125 What other road users or objects in the road were involved in your crashes? (please select all that apply)

Motor vehicle (1)

Another cyclist (2)

Pedestrian (3)

A roadside object (tree/pole/parked car/etc.) (4)

A pothole or other object in road (5)

Loose gravel/sand or other debris (6)

Nothing - I lost control/fell over (7)

Other (8) 
Q71 How many times have you had a crash involving the following road users or objects in the road?

\begin{tabular}{|c|c|c|c|}
\hline & $1(1)$ & $2(2)$ & $\begin{array}{l}3 \text { or more } \\
\text { (3) }\end{array}$ \\
\hline Motor vehicle $(x 1)$ & & & \\
\hline Another cyclist (x2) & & & \\
\hline Pedestrian (x3) & & & \\
\hline $\begin{array}{l}\text { A roadside object (tree/pole/parked } \\
\text { car/etc.) (x4) }\end{array}$ & & & \\
\hline $\begin{array}{l}\text { A pothole or other object in road } \\
\qquad(x 5)\end{array}$ & & & \\
\hline $\begin{array}{l}\text { Loose gravel/sand or other debris } \\
\qquad(x 6)\end{array}$ & & & \\
\hline Nothing - I lost control/fell over ( $x 7)$ & & & \\
\hline Other (x8) & & & \\
\hline
\end{tabular}

Q126 Think about the worst crash... Who or what was involved?

$\boldsymbol{\nabla}$ Motor vehicle (1) ... Nothing - I lost control/Fell over (7)

Q150 What was the severity of the crash?

No injury (1)

Mild (scrapes, bruises) (2)

Moderate (cuts, bleeding) (3)

Severe (trip to hospital) (4)

Property damage (5) 
Q72 Do you think the e-bike significantly contributed to your crash or near miss?

Yes (please explain) (1)

No (2)

I don't know (99)

Q76 Do you think your e-bike has helped you avoid crashes?

Yes (please explain) (1)

No (2)

I don't know (99)

Q123 Section Five: Previous cycling experience

This section is about your experiences with standard bicycles. For the purpose of this survey, a standard bicycle has no assist and is only propelled by the rider.

Q80 Before owning an e-bike, did you as an adult ride a standard bicycle?

Yes (1)

No (2)

Q81 Before you owned an e-bike, how often did you ride a standard bicycle?

Never (1)

Once a year or less (2)

A few times a year (3)

Monthly (4)

Weekly (5)

Daily (6) 
Q83 How often do you ride a standard bicycle now?

Never (1)

Once a year or less (2)

A few times a year (3)

Monthly (4)

Weekly (5)

Daily (6)

Q85 Do you ride for different purposes or to different destinations or take different routes on your e-bike than you would on a standard bicycle?

Yes (1)

No (2)

Q86 If yes, please describe the reasons why you ride an e-bike for different purposes or to different destinations or take different routes than you would on a standard bicycle.

Q90 Please describe any other differences you have experienced in the way you ride your e-bike compared to a standard bicycle.

\section{Q155 Section Six: Final Thoughts}

Q93 Do you have any positive experiences using your e-bike that you would like to share with us?

Q94 Do you have any negative experiences using your e-bike that you would like to share with us?

Q95 Do you have any unique or interesting experiences regarding your e-bike that you would like to share with us?

\section{Q97 Section Seven: Demographics}

Thank you for participating in our survey! You are almost done. Please answer a few demographic questions so we can learn a bit more about you. 
Q99 Do you consider yourself (check all that apply)...

American Indian or Alaska Native (1)

Asian (2)

Black or African American (3)

Other (4)

White or Caucasian (5)

Hispanic or Latino/Latina (6)

Prefer not to say (7)

Q101 What is your age?

Q103 Are you...

Male (1)

Female (2)

Other (3)

I prefer not to answer (99)

Q105 What is the highest level of education you have completed?

High school or less (1)

Associates degree (3)

Graduate/Professional degree (5)

Some college, no degree (2)

Bachelor's degree (4)

I prefer not to answer (6) 
Q109 Are you currently employed?

Yes (1)

No (2)

I prefer not to answer (3)

Q113 Are you married or living with a partner?

Yes (1)

No (2)

Q115 Including yourself, how many people are in your household?

Adults (1)

Children (2)

Q119 What is your household's annual income?

Less than $\$ 15,000$ (1)

$\$ 25,000$ - \$34,999 (3)

$\$ 50,000$ - \$74,999 (5)

$\$ 100,000$ - \$149,999 (7)

I prefer not to answer (99)

$\$ 15,000$ - \$24,999 (2)

$\$ 35,000$ - \$49,999 (4)

$\$ 75,000$ - \$99,999 (6)

$\$ 150,000+(8)$ 
Q124 How would you describe your general state of health?

\section{Excellent (1)}

Very good (2)

\section{Good (3)}

\section{Fair (4)}

Poor (5)

I prefer not to answer (6)

Q154 How many days per week do you get at least 30 minutes of moderate and vigorous physical activity? Moderate physical activity is activities or exercise like walking, low-impact cycling, general yard work, dancing or e-biking. Vigorous physical activity is activities or exercise like intense cycling, running, sports, or calisthenics.

\section{$\begin{array}{llllllll}0 & 1 & 2 & 3 & 4 & 5 & 6 & 7\end{array}$}

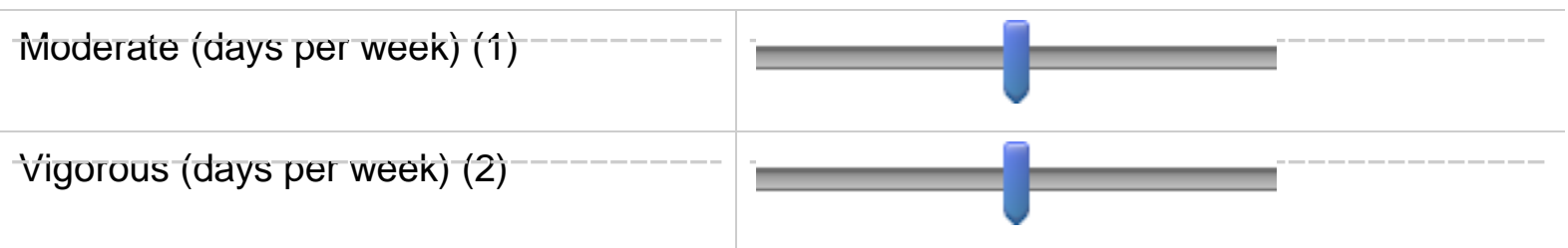

Q126 Do you have any physical limitations that make riding a standard bicycle difficult for you?

Yes (1)

No (2)

I prefer not to answer (3)

Q127 If yes, would you please share with us the type of limitations? 
Q128 How many working motor vehicles are currently in your household? (please do not include RVs, motor homes, or off-road vehicles)

$0(1)$

$1(2)$

$2(3)$

$3(4)$

$4(5)$

5 or more (6)

Q129 How many functional adult bicycles (standard and electric bicycles) do you have in your household that you could use?

$0(1)$

$1(2)$

2 (3)

$3(4)$

$4(5)$

5 or more (6)

Q130 Do you have a driver's license?

Yes (1)

No (2) 
Q168 How did you hear about this survey? (Select all that apply)

An e-mail from an e-bike store (1)

A post from an e-bike manufacturer's social media account (2)

A friend told me about the survey (3)

An e-mail from an e-bike manufacturer (6)

A post from an e-bike store's social media account (5)

Other (4)

Q159 Thank you for taking the time to respond to our survey! You are almost done.

We have tried to limit the initial survey but we do have a couple more questions. Would you like to answer a few additional questions about your experiences with e-bikes? You'll help us out a lot. You responses will allow us to learn more about how people choose and use their e-bikes.

If you select "No", you will be sent to the end of the survey.

Yes (1)

No (4)

Q160 Thanks for sticking with the survey. Here are few additional questions. 


\section{Additional Section}

Q77 Would you be comfortable riding a bike (standard or e-bike) in the following places?

$\begin{array}{ccccc}\begin{array}{c}\text { Very } \\ \text { comfortable }\end{array} & \begin{array}{c}\text { Somewhat } \\ \text { comfortable }\end{array} & \begin{array}{c}\text { Somewhat } \\ \text { uncomfortable }\end{array} & \begin{array}{c}\text { Very } \\ \text { uncomfortable }\end{array} & \begin{array}{c}\text { I don't } \\ \text { know (5) }\end{array} \\ (1) & (2) & (3) & (4) & \end{array}$

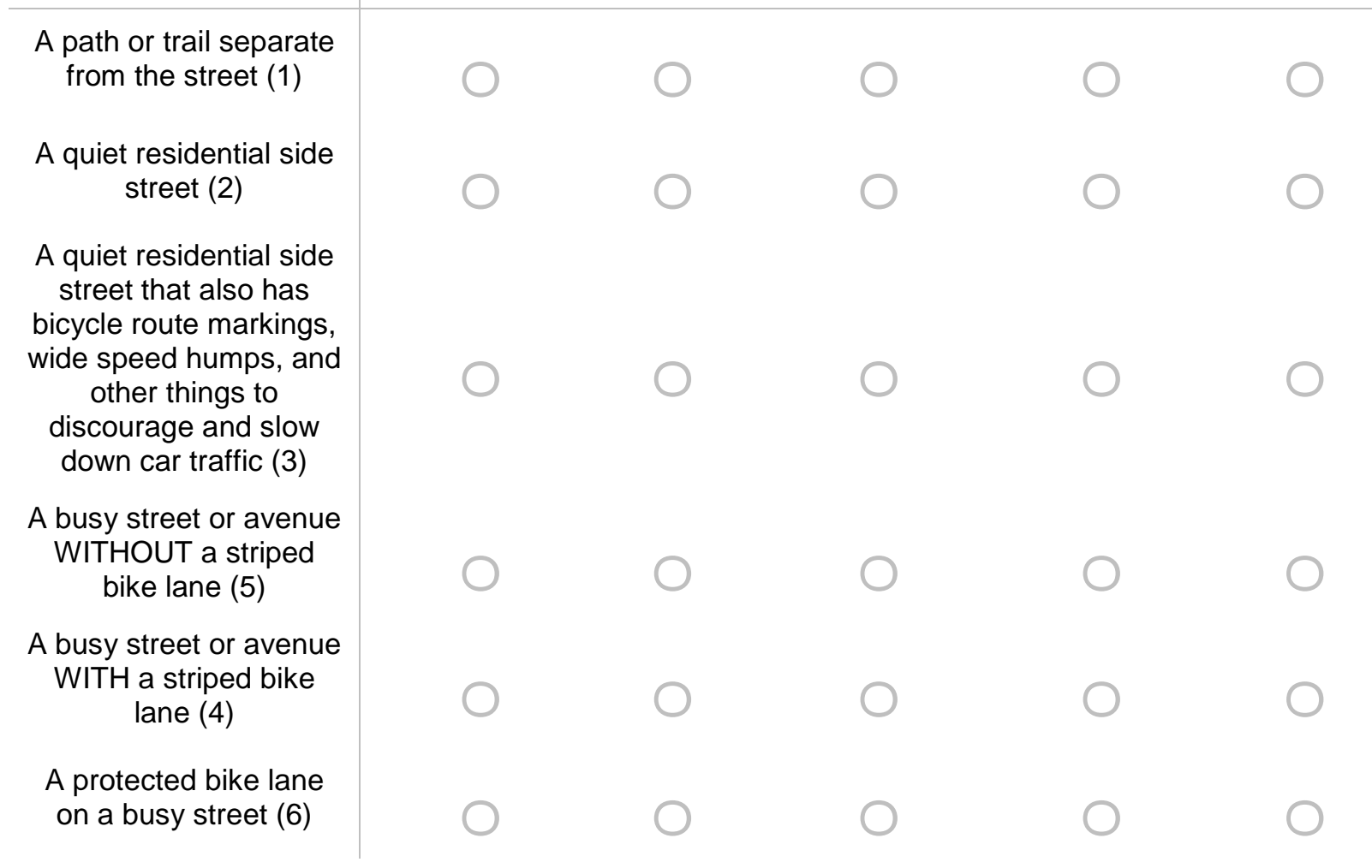

Q55 When riding an e-bike, how often do you...

\begin{tabular}{c|ccccc} 
& Never (1) & $\begin{array}{c}\text { Occasionally } \\
(2)\end{array}$ & $\begin{array}{c}\text { Sometimes } \\
(3)\end{array}$ & $\begin{array}{c}\text { Most } \\
\text { times (4) }\end{array}$ & $\begin{array}{c}\text { Always (5) } \\
\text { I don't } \\
\text { know } \\
\text { (99) }\end{array}$ \\
\hline $\begin{array}{c}\text { Completely stop } \\
\text { and wait at red } \\
\text { traffic lights (1) }\end{array}$ & 0 & 0 & 0 & 0 & 0 \\
$\begin{array}{c}\text { Completely stop at } \\
\text { stop signs (2) }\end{array}$ & 0 & 0 & 0 & 0
\end{tabular}


Q21 Before purchase, where did you get information about the types of e-bikes/conversion options available? (Please select all that apply)

\section{Magazines (1)}

Internet/Websites/Blogs (2)

Visited retailers (3)

Family/friend/colleague who had an e-bike (4)

Test ride event (5)

Other (Please specify) (6)

Q23 At the time of purchase, did you consider...

\begin{tabular}{c|ccc}
\hline $\begin{array}{c}\text { Different motor technologies (e.g. hub } \\
\text { motor, crank motor) (1) }\end{array}$ & $\begin{array}{c}\text { Did not } \\
\text { consider (1) }\end{array}$ & $\begin{array}{c}\text { Some } \\
\text { consideration } \\
(2)\end{array}$ & $\begin{array}{c}\text { Serious } \\
\text { consideration (3) }\end{array}$ \\
Battery range (3) & 0 & 0 \\
Bike type/style (5) \\
$\begin{array}{c}\text { Type of assist (pedal-assist or throttle) } \\
(6)\end{array}$ \\
Price (7)
\end{tabular}

Q33 How often have you had your e-bike serviced because of an issue related to the battery, motor or electronic system?

No service needed to date (1) ... 5 or more times (6) 
Q34 Why did you need to have your e-bike serviced other than normal bicycle related tune-ups or fixes?

Repairs to the electronics/display (1)

Repairs to motor (2)

Replace battery (3)

Other (Please specify) (4)

Q36 Have you had any specific problems with how your e-bike functions? If so, please describe.

Q53 Have you ever had any reactions - positive or negative - from other road users? Please briefly explain your experiences.

Q158 Have these things happened to you?

Yes (1) No (2)

Has the battery ever run out of

power on a ride? (1)

Have you ever had your e-bike stolen? (2)

Has the weight of the e-bike ever prohibited you from using it for certain activities? (3)

Q157 What would you tell or share with someone/friend who is considering purchasing an e-bike?

Q167 Thank you for completing the survey! If you have any questions about the study, please contact us at macarthur@pdx.edu or 503-725-2866. Click on the blue forward arrow to be redirected to a page where you can enter our drawing for one of $10 \$ 50$ Visa Gift Cards. 
Transportation Research and Education Center

Portland State University

1900 S.W. Fourth Ave., Suite 175

Portland, OR 97201 